\title{
REFLEXIONES SOBRE LA ÚLTIMA FASE DE LA NECRÓPOLIS OCCIDENTAL DE LA CIUDAD ROMANA DE VALENTIA*
}

\author{
REFLECTIONS ON THE LAST PHASE OF THE OCCIDENTAL NECROPOLIS OF THE ROMAN CITY \\ OF VALENTIA
}

\author{
JOSÉ LUIS PORTILLO SOTELO \\ Universidad de Cádiz \\ joseluis.portillo@uca.es \\ https://orcid.org/0000-0002-6139-9065
}

Recepción: 31-03-2018

Aceptación: 02-07-2018

\section{Resumen}

Con este trabajo se pretende revisar la documentación y el material más tardío (parte de él inédito) de la necrópolis occidental de Valentia. Las investigaciones previas no consiguen ponerse de acuerdo sobre el momento de abandono de este espacio funerario, ya que hemos de tener en cuenta que los ajuares de las tumbas comienzan a desaparecer paulatinamente a partir del s. II d.C., provocando un vacío de información para esta última fase.

De los materiales con los que contamos destacan los de cerámica común, producción que nos va a interesar particularmente ya que la evolución de alguna de sus formas serán determinantes para fijar una cronología que en el caso de la necrópolis occidental nos remite al s. III d.C.

Palabras clave. Valentia; necrópolis occidental; cerámica común romana; urceus; calix; trulla; tintinnabulum.

\begin{abstract}
This work is intended to review the documentation and the latest material (part of it unpublished) of the occidental necropolis of Valentia. Previous investigations do not agree with the moment of abandonment of this funeral space, since the grave goods of the tombs begin to disappear gradually from the second century, causing an information gap for this last phase.

Among the materials we have, common pottery stands out especially. This production interests us particularly due to the evolution of some of its forms, crucial to establish a chronology that, in the case of the occidental necropolis, is the third century.
\end{abstract}

Key words. Valentia; Occidental necropolis; Roman common pottery; urceus; calix; trulla; tintinnabulum.

\footnotetext{
* Esta publicación es resultado del Trabajo Final de Máster defendido en la Universitat de València en septiembre de 2017. Agradecimientos: a mí tutor, Ferran Arasa i Gil; al Ajuntament de València y al Servicio de Investigación Arqueológica Municipal (SIAM), así como a su personal (Albert Ribera, Vicent Lerma, Merche González...); a Miquel Rosselló; y especialmente, a Esperança Huguet, por sus consejos y asesoramiento en el proceso de investigación.
} 


\section{HISTORIA DE LA INVESTIGACIÓN DE LA NECRÓPOLIS OCCIDENTAL}

Siguiendo las pautas en la situación de los espacios funerarios en el Imperio romano, la necrópolis occidental de Valentia se ubicaba al exterior del recinto de la ciudad, a unos $500 \mathrm{~m}$ al oeste del foro romano, en una pequeña elevación del terreno aún perceptible en la actualidad. Como era habitual en las prácticas funerarias romanas, vemos que estas tumbas se situarían en las inmediaciones de una de las principales rutas de acceso a la ciudad, la vía que da acceso a Valentia por el lado oeste y lleva al decumanus maximus (Machancoses, 2015).

La primera excavación se llevó a cabo entre 1992 y 1993 en la C/ Virgen de la Misericordia n. ${ }^{\circ} 4$ $\left(1 \mathrm{MIS} 04^{1}\right)$, situada al norte de la vía. Fue en 1991 cuando tras un sondeo realizado por el SIAM se descubrieron niveles arqueológicos, haciéndose necesaria una intervención previa a la edificación del solar para documentar adecuadamente los restos de la zona (Rosselló, 1993).

Los resultados de esta excavación dieron a conocer la necrópolis más antigua de la ciudad, con una cronología que va desde el s. I a.C. hasta el IV d.C. En esta primera toma de contacto se pudieron obtener interesantes datos relativos a la ciudad de Valentia, ya que, por su antigüedad, en ella se hallan enterradas las primeras generaciones fundadoras de la colonia. También es importante señalar la gran cantidad de restos arqueológicos que aparecieron en esta excavación, más numerosos en los ajuares de las tumbas más antiguas, es decir, en aquellos enterramientos del s. I d.C., mientras que su número desciende paulatinamente a partir del II, desapareciendo por completo para el s. III d.C., motivo por el que se nos hace tan difícil fijar una fecha de abandono. En cuanto a las prácticas funerarias, es necesario resaltar que prevalece la inhumación $(95,4 \%$, en un total de 103 tumbas), mientras que la incineración es minoritaria, testimonial incluso $(4,6 \%$, solo presente en cinco tumbas) (García-Prósper et al., 2003; Machancoses, 2015: 657).

La segunda intervención se realizó también al norte de la vía, en la $\mathrm{C} /$ Cañete n. $^{\circ} 4$ que se extiende hasta la $\mathrm{C} /$ Quart n. ${ }^{\circ} 48-55$. En total se realizaron cinco campañas arqueológicas desde 1996 hasta el año 2000 (1CAÑ004, 2CAÑ004, 3CAÑ004, 4CAÑ004

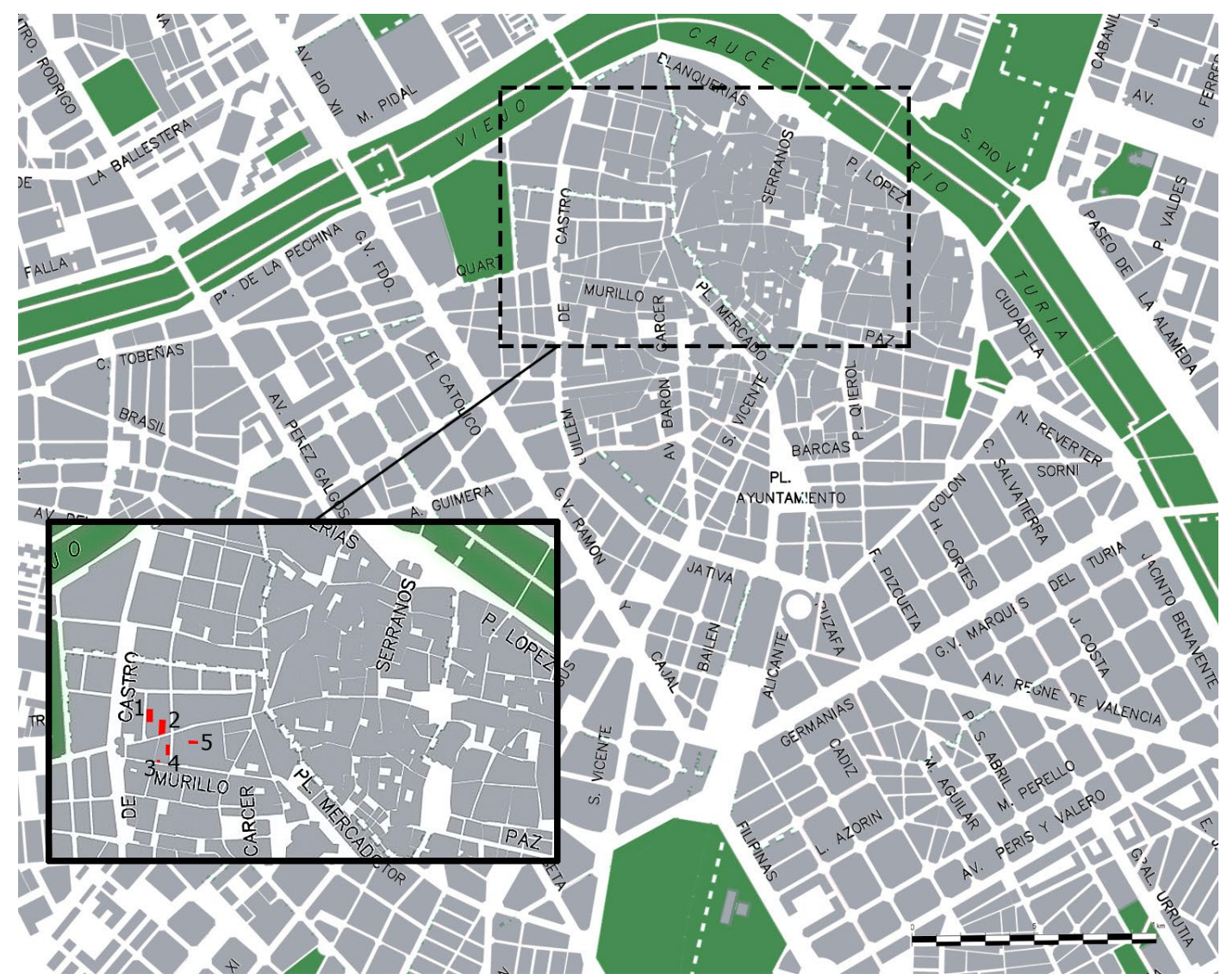

Figura 1: Situación de la necrópolis occidental de Valentia e intervenciones realizadas: 1.- C/ Virgen de la Misericordia n. ${ }^{\circ} 4$ (19921993); 2.- C/ Cañete n. ${ }^{\circ} 4-\mathrm{C} /$ Quart n. $^{\circ} 48-55$ (1996-2000); 3.- C/ Murillo n. ${ }^{\circ} 38$ (2006); 4.- C/ Carrasquer n. ${ }^{\circ} 2-4$ (2011); 5.- C/ Palomar n. ${ }^{\circ} 12$ (2012).

1. Referencia del SIAM para esta intervención. 
y 5CAÑ004), las cuales supusieron un gran avance en el estudio de esta necrópolis, principalmente por la gran cantidad de tumbas halladas, así como por el abundante ajuar que las acompañaba (García-Prósper, 2000).

Estas excavaciones también nos permitieron establecer una cronología más segura que las realizadas en la C/ Virgen de la Misericordia, abarcando desde el s. II a.C. hasta finales del II e inicios del III d.C. (Polo y García-Prósper, 2002). La realidad es que la gran concentración de tumbas halladas nos deja un panorama en el que encontramos hasta cuatro capas superpuestas de inhumaciones e incineraciones, lo que dificulta enormemente la datación de la necrópolis, siendo a día de hoy un tema aún no esclarecido (Machancoses, 2015).

Más recientemente se han realizado otras intervenciones de pequeño tamaño, esta vez en la zona sur de la vía, donde se halla, como dijimos anteriormente, un desnivel con respecto a la zona norte. Estas excavaciones fueron las realizadas en la $\mathrm{C} /$ Murillo n. ${ }^{\circ} 38$ (1MURI38) y en la C/ Carrasquer n. ${ }^{\circ}$ 2-4 (1CARRA2/1CARRA4), en las cuales se hallaron pocas tumbas, todas de época imperial (Salazar, 2006; Ortega, 2011). Los datos ofrecidos por todas ellas nos hace sospechar que los primeros enterramientos aparecen en la parte norte de la vía (en la zona de la $\mathrm{C}$ / Cañete-Quart y la $\mathrm{C}$ / Virgen de la Misericordia), para finalmente pasar al otro lado de la vía, donde están las tumbas más tardías (Machancoses, 2015: 660).

La última intervención se realizó en la zona sur, en la $\mathrm{C} /$ Palomar n. ${ }^{\circ} 12$ (1PALO12), con nueve inhumaciones y dos cremaciones, así como una presencia mayor de restos cerámicos, que podemos datar entre finales del s. II d.C. e inicios del III (Pascual, 2012). La importancia de esta excavación de pequeño tamaño radica en que permite plantear la posible extensión de la necrópolis hacia el sur en época imperial (Fig. 1).

En lo que se refiere a la labor de investigación de los materiales, es importante señalar que ha sido estudiada únicamente una selección de los ajuares pese al buen estado de conservación en el que se hallan; en primer lugar por E. García Prósper (2015), que analiza los restos de la necrópolis occidental desde un punto de vista antropológico, centrando su investigación en los restos óseos ${ }^{2}$ y en las prácticas funerarias y tratando someramente el resto de materiales; y en segundo por E. Huguet (2016), que realiza un estudio global de la cerámica común de Valentia, para lo que analiza varias tumbas de Cañete-Quart, así como una de Palomar, dando como resultado un estudio ceramológico de gran utilidad para el presente trabajo.

\footnotetext{
2. Son numerosas las publicaciones de carácter eminentemente antropológico de las excavaciones en la $\mathrm{C} /$ Cañete-Quart (García-Prósper y Polo, 2003; Polo Cerdá et al., 2004; GarcíaPrósper et al., 2007; Polo Cerdá et al., 2009).
}

\section{1. ÚltTIMA FASE DE LA NECRÓPOLIS OCCIDENTAL}

Es interesante comprobar cómo los estudios realizados hasta la fecha sitúan el abandono de la necrópolis en el s. III d.C., hecho que debemos poner en consonancia con la situación de profundos cambios en la que se encontraba la ciudad: se reduce su perímetro y se abandonan zonas y edificios (incluso religiosos y grandes edificios públicos). En esencia, se produce un abandono parcial y una concentración de la población en la zona sureste, por lo que es de esperar que esta crisis se vea reflejada en los enterramientos de la necrópolis occidental, así como en su abandono y reemplazo por una nueva necrópolis en la zona sur, la de La Boatella, la cual comienza a utilizarse, precisamente, a partir del s. III d.C. (Rosselló, 1993; Rosselló y Ruiz Val, 1996b: 192).

Ante todo, debemos ser conscientes de la importancia de este espacio funerario: primera necrópolis de la ciudad y de enorme extensión, con un total de 244 enterramientos y una gran riqueza en sus ajuares. Es por ello por lo que se hace necesaria una exhaustiva revisión de los materiales arqueológicos menos estudiados (la mayoría inéditos, exceptuando algunos de relevante importancia), que coinciden con los de la última fase de la necrópolis, momento para el cual han desaparecido prácticamente los ajuares de las tumbas, lo que por otro lado proporciona aún más importancia al escaso material que podamos vincular a esta fase.

Es necesario puntualizar la complejidad que conlleva el estudio del material de esta necrópolis, tanto por su enorme cantidad como por el tiempo que ha transcurrido desde que se realizaron las excavaciones, cuando la metodología no era tan eficaz como en la actualidad. A todo esto, hemos de añadir la dispersión de parte de la documentación y la dificultad de acceso a algunos materiales, consecuencia precisamente del lapso de tiempo transcurrido.

Así pues, el objetivo de este estudio ha sido la revisión del material tardío con la finalidad de conseguir fijar definitivamente el momento de abandono de la necrópolis y poder ponerla así en relación con las conocidas transformaciones que experimenta la ciudad en el s. III d.C., así como la situación y fundación de una nueva necrópolis, la mencionada de La Boatella, en el sureste de la ciudad.

\section{ENTERRAMIENTOS DEL S. III D.C.}

Tras la revisión de toda la documentación y del material arqueológico disponible de estas intervenciones hemos seleccionado aquellos enterramientos tardíos con presencia de ajuar, que como puntualizamos anteriormente desaparece prácticamente en su totalidad para el s. III d.C., dejándonos cerca de una decena de tumbas que cumplan este requisito. Los más numerosos los hallamos en la intervención realizada en la C/ Cañete-Quart en el año 1998. 


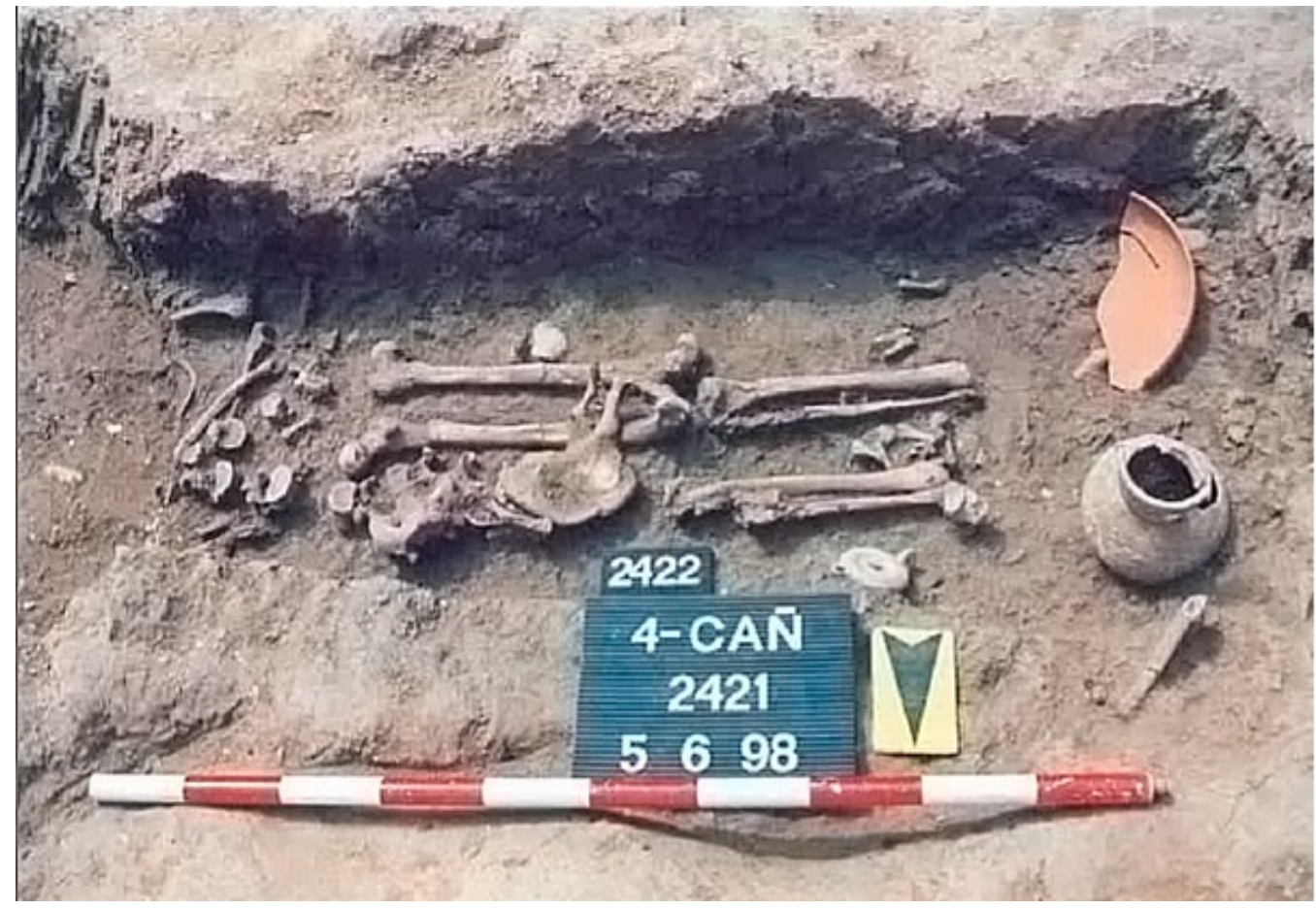

Figura 2: Enterramiento UE 2422 acompañado del ajuar funerario: lucerna africana Dressel 20 (NIM 0631), jarra africana Tolegassos 489-490 (NIM 0631) y fuente de africana de cocina Hayes 181C (NIM 0632). Editado a partir de García-Prósper, 2015.

El primero de los enterramientos se trata de una inhumación (UE 2156) de fosa trapezoidal orientada E-O; no obstante, la tumba se encuentra levemente alterada por la presencia de una cremación (UE 2164) y una calzada con orientación N-S (UE 2152) (García-Prósper y Guérin, 1999: 32-33). El estudio antropológico desvela que se trata de una mujer adulta de entre 40-45 años, con el cuerpo orientado E-O y en posición decúbito supino con la cabeza ladeada hacia la izquierda; según los indicadores patológicos, este individuo desarrolló una actividad continuada en brazos y piernas como consecuencia, posiblemente, de actividades laborales constantes e intensas. Finalmente el ajuar está formado por un olpe $\left(\mathrm{NIM}^{3}\right.$ 0614) y una trulla de cerámica común (NIM 0615) (García-Prósper, 2015: 293-294).

La segunda inhumación (UE 2422), esta vez de dos individuos, se localiza también en el sector sur de la excavación. De fosa rectangular y con orientación E-O, se encuentra cortada por un pozo medieval en la zona de la cabecera, donde no se observan vestigios materiales ni óseos (García-Prósper y Guérin, 1999: 42). Se trata de dos individuos jóvenes adultos, de 20-25 años, que pese al bajo índice de conservación de los esqueletos se han podido identificar como un varón y una mujer (Fig. 2). También se halló en el relleno un total de siete clavos de hierro (N. ${ }^{\circ}$ Inv. 576) de diversos tamaños, que debieron formar parte de una caja mortuoria. El

3. Referencia del SIAM para las piezas. NIM (Número de Interés Museístico) y N. ${ }^{\circ}$ Inv. (Número de Inventario). ajuar apareció situado a los pies de la tumba, lo que ha permitido su conservación ya que no se ve afectado por la mencionada alteración medieval de la cabecera. Este estaba formado por una lucerna africana (NIM 0661), un olpe de cerámica común africana (NIM 0631) y una fuente de africana de cocina (NIM 0632). También es destacable el hallazgo de restos óseos de un perro de edad adulta a los pies del difunto (García-Prósper, 2015: 316-318).

La tercera tumba (UE 2183) consta de una fosa trapezoidal con orientación E-O. El esqueleto, en decúbito supino, pertenece a una mujer joven adulta de 21-25 años que presenta marcadores de estrés ocupacional en brazos y piernas, y evidencias de enterramiento en ataúd, como se aprecia en la posición de las extremidades superiores y en la presencia de clavos de hierro (N. ${ }^{\circ}$ Inv. 535). El relleno de la fosa cuenta con abundantes restos cerámicos, siendo importantes dos cuencos de cerámica común (NIM 0628-0629), una lucerna (NIM 0659) y un olpe de cerámica común (NIM 0616) (García-Prósper y Guérin, 1999: 73-74; García-Prósper, 2015: 415-417).

El cuarto de los enterramientos se trata de una cremación (UE 2053) de la que destacamos principalmente la urna cineraria, un olpe de cerámica común de gran tamaño (NIM 0654). No se pudo localizar el loculus o nicho donde se habrían depositado los restos originalmente debido a alteraciones contemporáneas; en cuanto al estudio antropológico, se ha podido identificar a dos individuos, una mujer adulta de 20-40 años y un infante de 7-12 años (García-Prósper y Guérin, 1999: 69; García-Prósper, 2015: 443). 
La siguiente inhumación seleccionada (UE 2322) consta de una fosa rectangular con orientación E-O y esqueleto en posición decúbito supino (García-Prósper y Guérin, 1999: 60-61). Se trata de una mujer con un rango de edad adulto senil, mayor de 60 años, lo que se aprecia patológicamente en el desgaste de las extremidades y en la dentadura. En el relleno observamos cantidad de material arqueológico, del que destacamos un anillo de bronce de sección ovalada (N. ${ }^{\circ}$ Inv. 560) que ha dejado marcas de oxidación en la mano izquierda del esqueleto; sin embargo, para el estudio ceramológico que nos atañe, la pieza más destacada es un olpe de cerámica común (NIM 0621) (GarcíaPrósper, 2015: 380-381).

La sexta inhumación (UE 2255) también consta de fosa rectangular con orientación E-O. El esqueleto pertenece a una mujer adulta de 33-40 años que presenta evidencias de descomposición en vacío, y que junto al hallazgo de siete clavos (N. ${ }^{\circ}$ Inv. 448-450) atestiguan la presencia de un ataúd. El ajuar está compuesto por un olpe de cerámica común (NIM 0633) que, según el informe de excavación, se encontró junto a un cuenco de vidrio del que no se aporta más información (GarcíaPrósper y Guérin, 1999: 77-78; García-Prósper, 2015: 421-423)

La séptima inhumación se trata de un enterramiento infantil (UE 2294) de fosa rectangular y orientación E-O. Estamos ante un infante de 7 años y un metro de altura enterrado en decúbito supino; el estudio antropológico evidencia una descomposición en vacío fundamentalmente por la posición de las extremidades y la patología de las articulaciones. Finalmente, el ajuar, situado a los pies, está formado por una copa de TSA A (NIM 0650) y una jarra-biberón de vidrio (NIM 0651) (García-Prósper y Guérin, 1999: 78-79; García-Prósper, 2015: 426-427).

Destaca también la Tumba 72 (Fig. 3) de la intervención realizada en la $\mathrm{C} /$ Virgen de la Misericordia, cuyo ajuar se compone únicamente por una jarrita de TSA A (Rosselló y Ruiz Val, 1996a).

Finalmente, de la intervención realizada en 2012 en la C/ Palomar por G. Pascual Berlanga (2012: 43, 49), hemos de destacar la Tumba 10. En ella hallamos abundantes restos cerámicos que abarcan amplias cronologías, como una sartén de engobe rojo pompeyano; no obstante, un posible tintinnabulum (n. $\left.{ }^{\circ} 1331-1 / 2\right)$ y un as de Diva Faustina nos aproximan al último tercio del s. II e incluso quizás a inicios del III d.C.

4. Los trabajos de reorganización de los fondos arqueológicos de la necrópolis Cañete-Quart en el SIAM no han permitido por el momento la localización de esta interesante pieza.

5. No disponemos de muchos más datos de este enterramiento debido a la dificultad en la localización de la documentación arqueológica y las fichas de unidad estratigráfica.

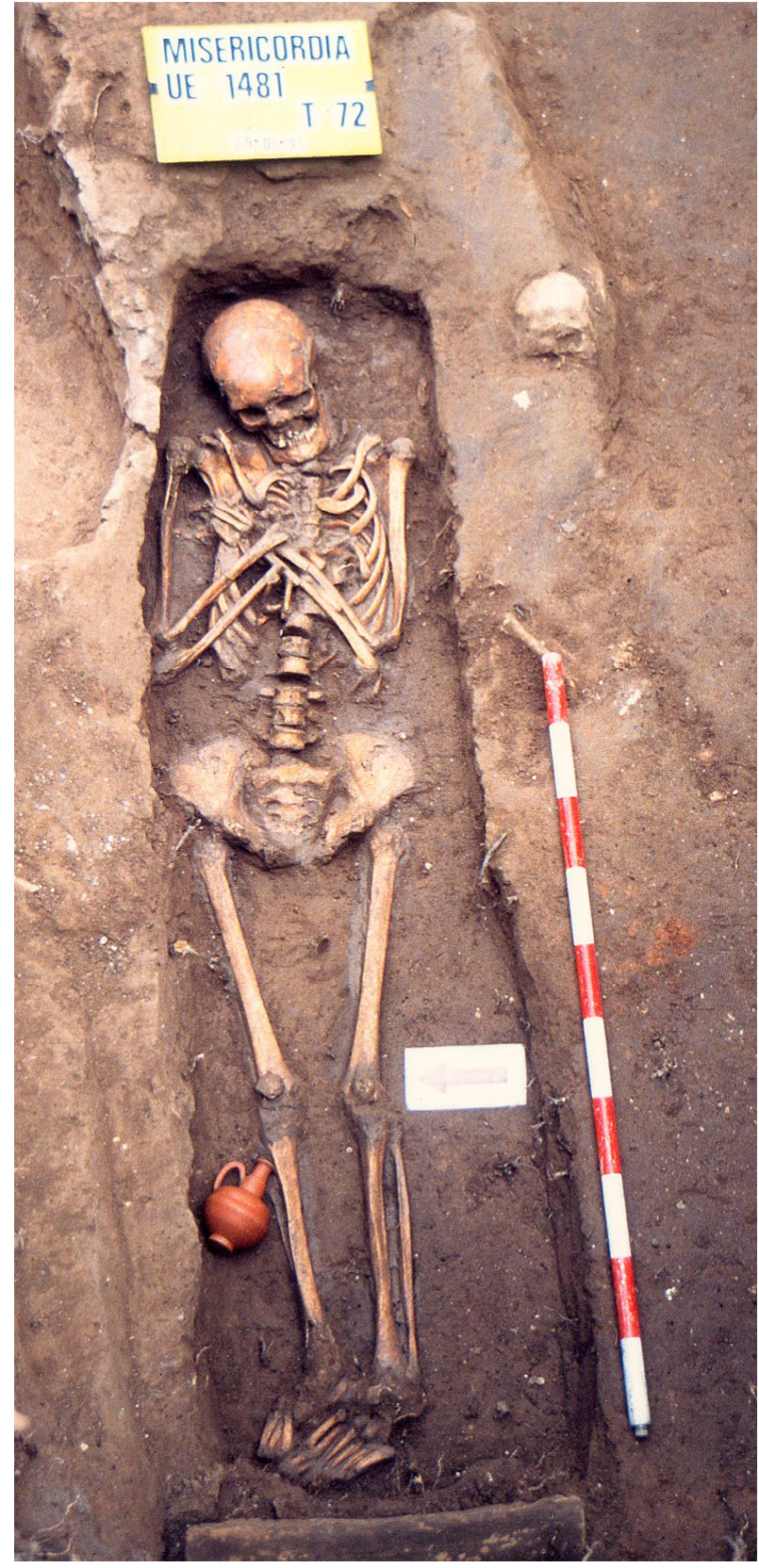

Figura 3: Tumba 72 de la intervención en la C/ Virgen de la Misericordia con jarrita de TSA A Hayes 160. Modificado a partir de Rosselló, 1993.

\section{ESTUDIO CERAMOLÓGICO DE LOS AJUA- RES}

\subsection{ProducCiONES EN CERÁMICA COMÚN}

Como hemos podido ver, es la cerámica común la que predomina en los ajuares. Es bien sabido que a estas producciones no siempre se les ha prestado demasiada atención por parte de la investigación, aunque desde el trabajo pionero de M. Vegas (1973) han sido objeto de interesantes estudios monográficos. Es precisamente a partir de este estudio cuando se ha ido desechando la idea generalizada de que sus formas se fabrican sin 
cambios durante largos periodos de tiempo, lo que reducía considerablemente su utilidad a nivel arqueológico. En la actualidad, en Valencia, contamos con la tesis doctoral de E. Huguet (2016), donde se analizan las diferentes tipologías de cerámica común, así como la evolución cronológica de los tipos más representativos, lo que nos proporciona la base idónea para afrontar el estudio de los urcei, jarritas y cuencos que componen, en su mayoría, los ajuares de los enterramientos más tardíos de la necrópolis occidental.

\subsubsection{Olpe Vegas 44/Gr. I.2 Urceus}

La forma más recurrente en estos ajuares es el olpe Vegas 44 o Gr. I.2 Urceus ${ }^{6}$ (NIM 0614/0616/0621/0633/0654). Se trata de jarritas de labio redondeado, cuello estrecho con estrías en la superficie interna y externa, cuerpo piriforme con la panza baja, generalmente de base plana, y de una sola asa con sección en forma de cinta; su cocción es oxidante, con pasta de núcleo gris y desgrasante de pequeño tamaño con restos blancos y brillantes. La superficie es beige con trazas grises horizontales en cuerpo y borde, y verticales, en el asa (Figs. 4 y 7, n. ${ }^{\circ}$ 4, 5, 6, 8 y 9).

Esta forma aparece abundantemente en la cuenca del Mediterráneo occidental y se fecha laxamente desde el s. I hasta el IV d.C., período en el que experimenta una evolución en su forma, manteniendo siempre una serie de características en común. En Valentia será la más común durante el Alto y Medio Imperio, sufriendo una evolución morfológica que queda patente en la disminución del tamaño de las piezas, así como en la pérdida de una de las asas y su consecuente estrechamiento (Fig. 5) (Escrivà, 1995; Huguet, 2016: 297-298).

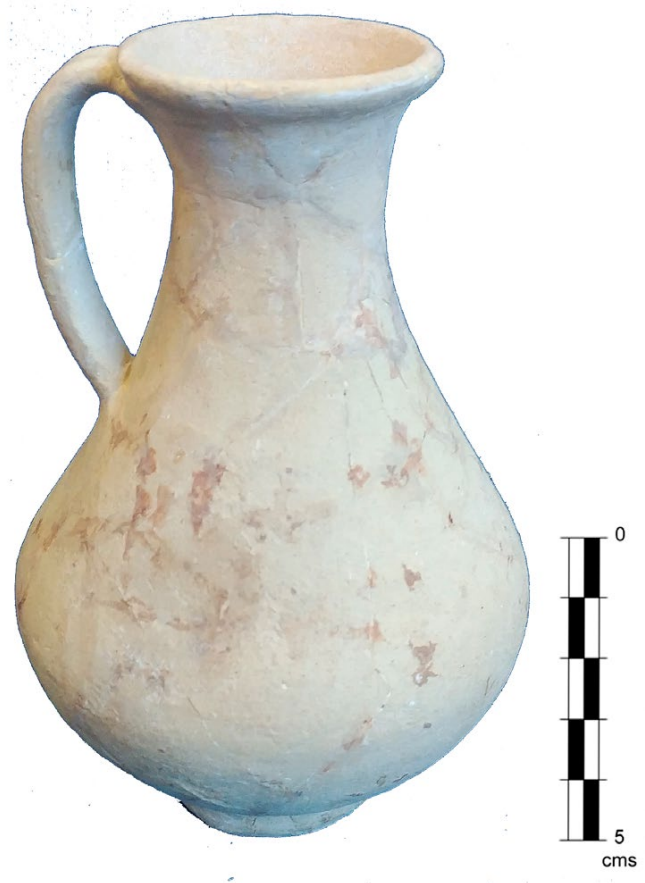

Figura 4: Jarrita Gr. I.2 Urceus, mitad del s. III d.C. (NIM 0621). Fotografía: E. Huguet.

Encontramos paralelos de esta forma en yacimientos como Albintimilium o Pollentia, en la C/ Porticada y la Casa Noroeste, siempre en contextos que oscilan entre finales del s. II e inicios del III d.C. (Vegas, 1973: 103, 112; Sánchez Fernández, 1983; Olcese, 1993). Entre los yacimientos más cercanos a Valencia, destaca la villa romana de La Vallaeta M15.3 (Sagunto), donde comprobamos que la forma Gr. I.2 Urceus es la más abundante, con más de medio millar de individuos en contextos que se fechan en el s. III d.C. (Huguet, 2009:

\section{Evolución de los Urcei en Valentia}

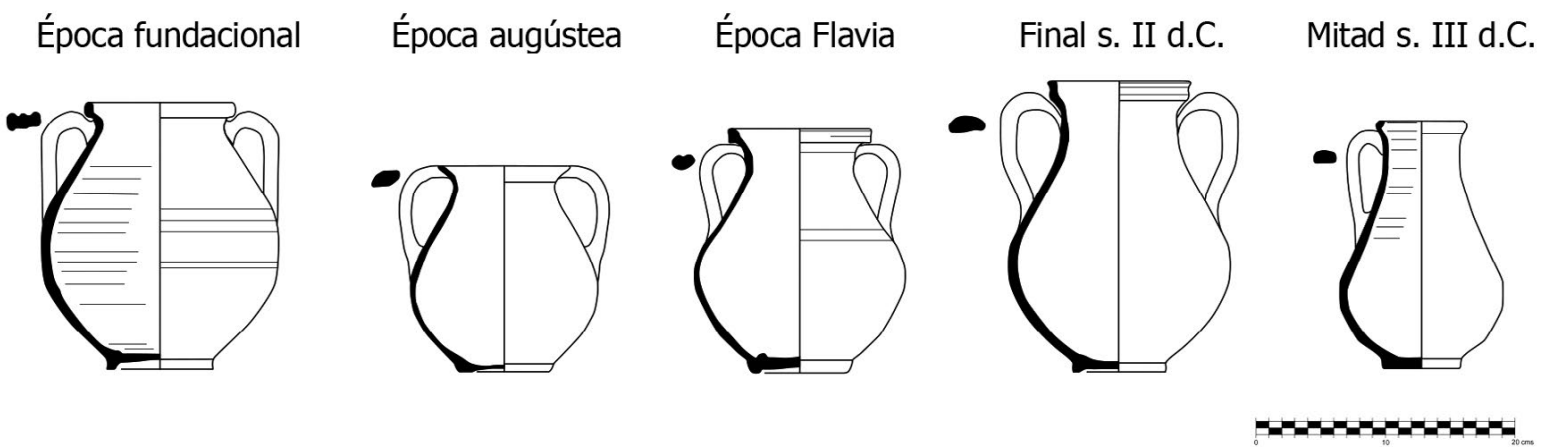

Figura 5: Evolución de los Urcei en la ciudad romana de Valentia. Editado a partir de Huguet, 2016.

6. La problemática del estudio de la cerámica común reside en la enorme variedad regional de sus producciones y en la complejidad que supone apreciar cambios morfológicos significativos en sus formas. Es por ello que para el estudio de la cerámica común hemos seguido la tipología propuesta por V. Escrivà
(1995) en su investigación de los materiales hallados en los pozos votivos de la ciudad de Edeta (Llíria), uno de los cuales, de época severiana, le permitió la comparación de esas formas con otros hallazgos tanto en Edeta como en La Vallaeta y en las proximidades (Huguet, 2009: 96-97). 
97-99). También en la ciudad de Edeta (Llíria), en la C/ Casaus n. ${ }^{\circ} 12$, se halló un pozo ritual con un conjunto cerámico del s. III d.C., en el cual tenían gran presencia estos urcei evolucionados (Escrivà et al., 2014: 248250, 252-254).

En la ciudad de Valencia contamos con muchos ejemplos de contextos con estos olpes y de similar cronología, como en la $\mathrm{C} /$ del Mar o en la Avda. de la Constitución $n$. $^{\circ} 58$, en el cual se halló una zona de producción alfarera, de donde hemos de destacar una fosa de desechos de cocción (UE2070) con gran representación de estas jarritas tipo Gr. I.2 Urceus (Huguet et al., 2008: 161-162; Huguet, 2016). Finalmente, también hallamos esta forma en la necrópolis de La Boatella, donde se vincula a los momentos iniciales de uso de esta área funeraria, en el s. III d.C. (Soriano, 1989).

Algunos de los enterramientos en los que aparecen estas jarritas se han vinculado con la corta edad de sus difuntos; ejemplo de ello lo tenemos en la necrópolis de Orriols, donde aparecen como ajuar de infantes. Los análisis químicos realizados a los paleocontenidos de algunos recipientes, entre los que hallamos algún urceus evolucionado, atestiguaron la presencia de ácidos grasos de la composición de leche animal y humana, evidenciando presuntamente su uso en los rituales funerarios de difuntos de corta edad. En el caso de la necrópolis occidental no apreciamos homogeneidad en las edades de los difuntos (un infante y cinco adultos), aunque anecdóticamente sí en el sexo, ya que todas son mujeres. En los paralelos consultados tampoco encontramos una especial vinculación de estos olpes con enterramientos infantiles, lo que parece descartar esta hipótesis (Martínez Pérez, 2016).

\subsubsection{Cuenco Gr. III Calix}

Los cuencos Gr. III Calix (NIM 0628/0629) son otras de las formas evolucionadas de cerámica común que tenemos en los enterramientos de la necrópolis occidental, que probablemente se usarían, de forma generalizada, para beber (poculum) (Fig. 7, n. ${ }^{\circ} 2$ y 3 ). En la inhumación UE 2183 hallamos dos de estos boles, de cocción oxidante, donde podemos ver superficies bicromáticas (naranja y amarillo) debido a las marcas de apilamiento en el proceso de cocción, lo que por otro lado nos permite reconstruir la posición de estos boles durante dicho proceso (Huguet, 2016: 299).

Posiblemente estas producciones se correspondan con imitaciones de vajilla de mesa en cerámica común, como vemos en la similitud que tiene con la forma Vegas 20. La escasez de hallazgos de este tipo en la ciudad de Valentia durante los ss. I-II d.C. debe ponerse en relación con el auge productivo de este mismo tipo en paredes finas; algunos autores nos hablan de la influencia del taller de Rubielos de Mora (Teruel) entre el País Valenciano y Murcia, desde Sagunto a Cartagena. Ejemplo de ello lo tenemos en la villa romana de La Vallaeta, donde se han documentado cuatro de estos calixes que imitan claramente la forma de Rubielos de Mora 2.1, muy abundante en esta villa, ya que es la forma de paredes finas que acapararía el mercado en los ss. I-II d.C. (Melchor y Benedito, 2009; 236; Huguet, 2016).

No es extraño encontrar imitaciones en cerámica común de formas de paredes finas; testimonio de ello son algunas piezas halladas en Valencia, en la Avda. de la Constitución n. ${ }^{\circ} 58$ o en los Baños del Almirante, que imitan las decoraciones (hojas de piña) y las formas características de esta producción, todas ellas datadas en el s. I d.C. (Huguet et al., 2008). Sin embargo, estas imitaciones con el tiempo evolucionan y van perdiendo calidad, dejándonos cuencos de cuerpo redondeado, sin decoración y pastas más deficientes, aproximándose a los calixes que estamos estudiando.

La realidad es que pese a la patente similitud que existe entre la Rubielos de Mora 2.1 con estos calixes, estos cuencos son formas universales que nos recuerdan a tipologías de producciones, y por lo tanto de cronologías, muy diversas. Vemos semejanzas con las formas caliciformes de la cerámica ibérica (Bonet y Mata, 2008: 159), con la Lamboglia 25/26/27 de barniz negro (Py, 1993: 147), así como con la Ritterling 8 en TSG (Passelac y Vernhet, 1993: 577) e incluso con la Conspectus 36 en TSI (Ettlinger et al., 1990: 114-115).

Los contextos en los que se han hallado esta forma Gr. III Calix nos remiten al s. III d.C., como vemos en el conjunto de materiales de la C/ del Mar o en la necrópolis de Ruzafa, donde se hallaron tres de estos boles en las Tumbas 3, 5 y 7 (Huguet, 2016: 266-265). También en este caso contamos con paralelos en la necrópolis de La Boatella, donde estos cuencos se hallan, por ejemplo, formando parte de un conjunto cerámico (ajuar) integrado por un mortero Dramont D 2, una jarrita Gr. I Urceus y una botella Gr. II lagoena, cuya cronología se sitúa en el s. III d.C. (Soriano, 1989: 403-404).

\subsubsection{Olpe Bonifay 50/Tolegassos 489-490}

En una de las tumbas de la C/ Cañete-Quart contamos con otro olpe, esta vez de la forma Bonifay 50/ Tolegassos 489-490 (NIM 0631), de producción africana. Se trata de una jarrita de base plana, cuerpo globular, estriado en la zona inferior de la panza y una sola asa con sección en forma de cinta; el cuello es vertical, aunque con cierto abocinamiento, y acaba en un labio redondeado. La pasta es de color amarillento con abundante desgrasante de restos orgánicos y calcáreos de tonalidad blanca (Fig. 6 y 9, n. ${ }^{\circ}$ 2) (Casas et al., 1990: 250).

M. Bonifay (2004: 284-285) destaca la forma del cuello, estableciendo una relación cronológica según la cual se tiende a la verticalidad conforme nos acercamos a finales del s. III d.C., encontrándonos con un cuello totalmente vertical para el s. IV. En cuanto a la jarrita que nos compete, vemos cómo el cuello cuenta con cierto abocinamiento, abriéndose las paredes 


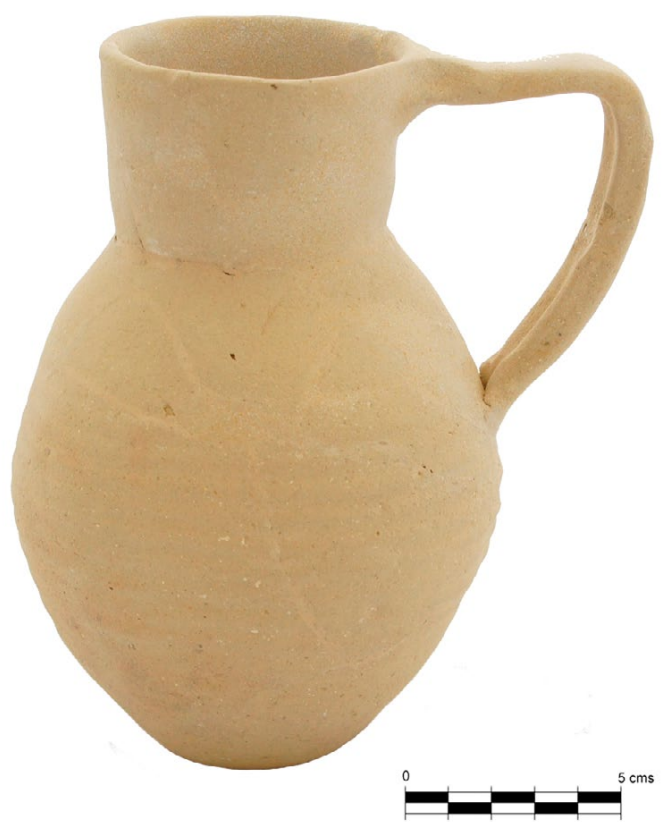

Figura 6: Jarra africana Bonifay 50/Tolegassos 489-490, s. III d.C. (NIM 0631). Fotografía: E. Huguet.

ligeramente al exterior, lo que rompe con la verticalidad y nos sitúa posiblemente en una cronología anterior (s. III d.C.).

Contamos con multitud de paralelos en la costa norte de África, como por ejemplo en Túnez, tanto en Nabeul, como en algunas tumbas de Raqqada (Olcese, 1993: 119; Bonifay, 2004). En las cercanías de la ciudad de Valencia hemos de destacar la villa gerundense de Tolegassos, donde a este tipo se le denominó como la forma 489-490. Lo hallamos también en un contexto funerario cerrado, en una de las sepulturas del Portus Ilicitanus, junto a un vaso de producción corintia donde se escenifican los trabajos de Hércules, y un ungüentario de vidrio Isings 82 , que nos remite al último cuarto del s. II e inicios del III d.C. (González Villaescusa 2001: 417).

También del s. III d.C. contamos con unos hallazgos en Carthago Nova, tanto en el Edificio del Atrio como en un contexto de incendio en la C/ Cuatro Santos, algo relevante cuando lo ponemos en relación con los hechos de crisis que vivió la ciudad, al igual que Valentia, durante este siglo, cuando se produjo el abandono de edificios públicos y privados, y se transformó el paisaje urbano, reduciéndose considerablemente su extensión (Noguera et al., 2017: 155-156; Quevedo, 2012; Quevedo y Bermejo, 2012: 127).

Algunos investigadores nos hablan de la posibilidad de que estas jarritas cuenten con una producción hispánica, incluso local o regional; así mismo, también se han querido vincular al mundo funerario, concretamente al uso del vino en sus rituales (Huguet, 2016: 464). Sin embargo, y aunque no descartamos del todo estas hipótesis, pensamos que la ausencia de evidencias, tanto en la necrópolis occidental como en los paralelos consultados, nos impiden compartir estos argumentos a falta de profundizar en el estudio de estas producciones cerámicas en la Península Ibérica.

\subsubsection{Trulla de cerámica común}

Otra pieza que forma parte de los ajuares de la necrópolis occidental es una trulla de cerámica común (NIM 0615). Consiste en un cazo de base plana, paredes verticales, mango horizontal en forma de cola de golondrina y el labio del borde marcado; la superficie es de tonalidad beige con desgrasante fino y trazas blancas y brillantes (Fig. 7, n. ${ }^{\circ}$ 7).

La denominación trulla se usa, de forma genérica, para hacer referencia a otras formas de la vajilla romana, lo que sucede principalmente por asimilación de este tipo con otros de material y forma diversos, aunque de funcionalidad similar. Por ello, no es extraño encontrar los términos de pátera, simpulum o cazo (cacerola/ cacillo) haciendo referencia a la trulla (Bustamante, 2012: 416, 424, 426-427). También se utiliza esta denominación para hacer referencia a cazos de metal con perforaciones que hacen las funciones de colador ${ }^{7}$, lo que nos da idea de su multifuncionalidad y de la variedad tipológica que engloba.

Este utensilio está destinado a diversos usos: para poner al fuego o para el servicio de vino u otros alimentos, siendo este su uso más aceptado, debido a su forma idónea para servir (mango largo horizontal) (Chofre, 1995: 271-272; Rosselló, 2005). Además de su uso como una pieza de la vajilla de mesa romana, se utiliza con una finalidad ritual, siendo este el aspecto que nos interesa (Pérez Outeiriño y Villaluenga, 19911992: 101).

Son mucho más frecuentes los hallazgos de trullae de material metálico, de los que se han documentado casos como la de Tiermes (Soria) (García-Bellido, 1966), la del Faro de Cullera (Valencia), Cáparra (Cáceres) o Alicante entre otros (Pozo, 2005: 40-41). En cuanto a los cazos cerámicos, proceden de la tradición de copiar en cerámica estas formas metálicas, hecho que se ha constatado de forma recurrente en épocas protohistórica y clásica con piezas de tipologías y formas muy diversas. También hallamos ejemplos de estas trullae en vidrio.

Los primeros cazos cerámicos se documentan a mediados del s. I d.C. en el sur de la Galia, como en La Graufesenque, en contextos rituales, y en Montans ya para el s. II d.C. Llegará un momento en el que las producciones de la Galia central (Lezoux) tomen fuerza con respecto a las del sur. Estas trullae elaboradas en la Galia y copiadas de las formas metálicas, estarán confeccionadas en TSG, de las que derivarán a su vez

7. Probablemente la palabra trulla proceda del griego trua o espumadera, por lo que parece ser que su funcionalidad inicial debía ser más similar a la de un colador que a la de un cazo para servir (López Gregoris, 2005: 90). 

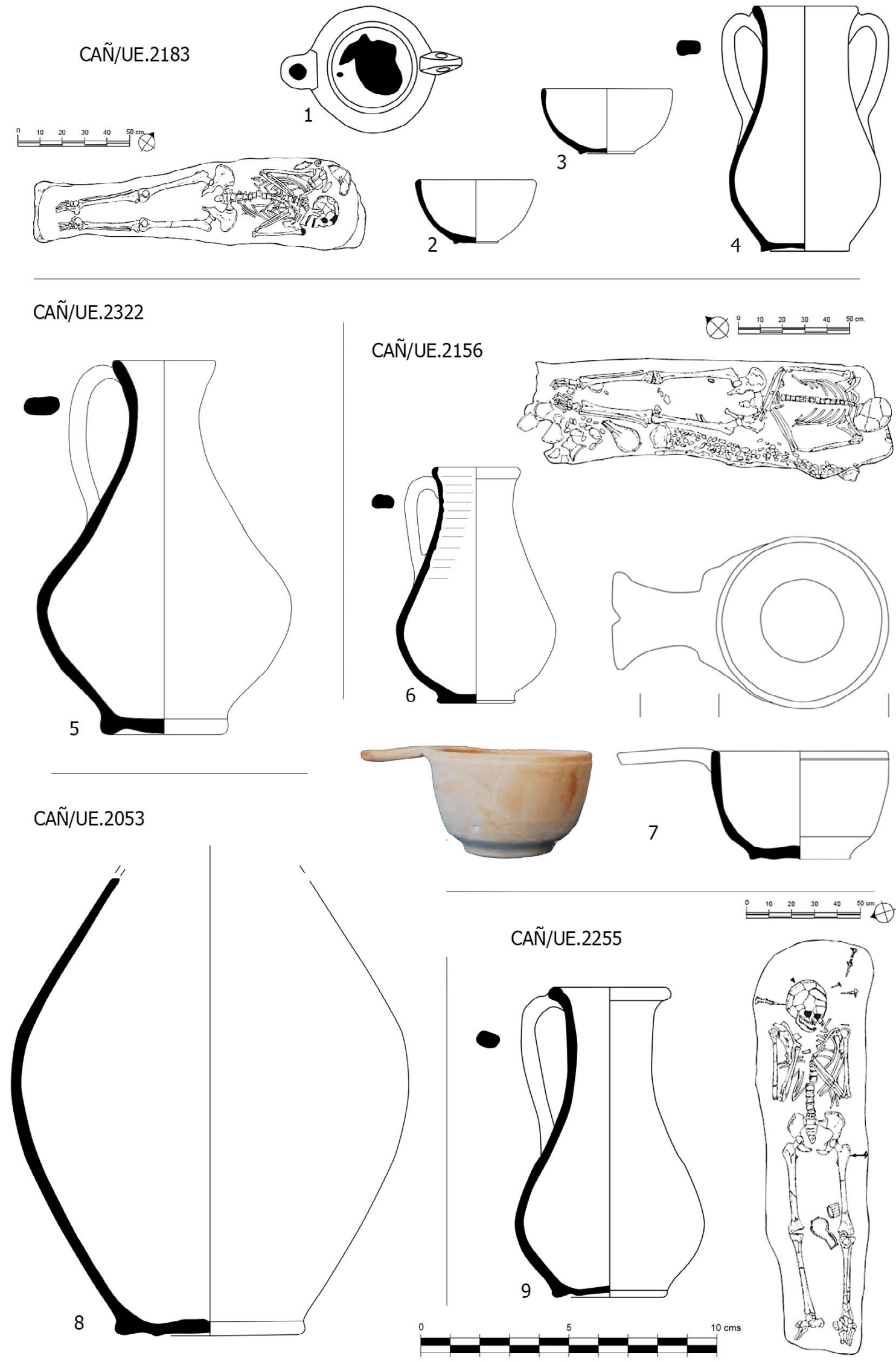

Figura 7: Enterramientos y ajuares de la necrópolis occidental: 1.- Lucerna Dressel 20 (NIM 0659); 2 y 3.- Cuencos Gr. III Calix (NIM 0628/0629); 4, 5, 6, 8 y 9.- Olpe Gr. I.2 Urceus (NIM 0616/0621/0614/0654/0633); 7.- Trulla de cerámica común (NIM 0615). Editado a partir de García-Prósper (2015) y Huguet (2016); 5 y 8, elaboración propia. 
las formas en TSH de finales del s. I e inicios del II. Sabemos que a partir de estas formas en T.S. Hispánica se copiarán en la Península Ibérica en otras producciones cerámicas, sin embargo, éstas están menos difundidas y estudiadas, como atestigua la escasez de referencias en la bibliografía especializada, lo que dificulta establecer paralelos que nos puedan ayudar a fijar una cronología (Pérez Outeiriño y Villaluenga, 19911992: 101-103; Huguet, 2015: 104).

Tenemos una trulla de cerámica común, de pasta blancuzca, en el Museo Nacional de Arte Romano de Mérida, de similares características a la que estudiamos. En esta ciudad también contamos con tres fragmentos de mango horizontal en paredes finas con una rica decoración a molde, lo que en este caso se alejaría de la pieza que estamos tratando (Pérez Outeiriño y Villaluenga, 1991-1992).

En las proximidades de Valentia destacamos tres mangos planos hallados en la villa de La Vallaeta (Sagunto), con forma de cola de delfín, pertenecientes a un cazo de paredes verticales ligeramente abiertas al exterior (Huguet, 2015). Recientemente también se ha documentado esta forma en la necrópolis de Algezares (Murcia).

La problemática la encontramos a la hora de situar cronológicamente esta tipología, pues como ya dijimos la falta de paralelos y de documentación bibliográfica nos dificulta esta tarea. En un principio, podríamos situarnos a partir del s. II, abarcando todo el s. III d.C., pese a que en la necrópolis de Ponti en Mariana (Córcega) la encontramos como parte de un ajuar del s. I d.C. De lo que parece que podemos estar seguros es de que no tenemos, hasta el momento, hallazgos de esta forma en Hispania anteriores al s. II d.C. (Huguet, 2016: 520).

\subsection{OTRAS PRODUCCIONES}

En el apartado anterior hemos revisado una serie de tipologías de cerámica común que nos remitían principalmente al s. III d.C.; no obstante, también hay piezas en otras producciones cuyas cronologías parecen $a$ priori más amplias y menos esclarecedoras.

\subsubsection{Fuente Hayes $181 \mathrm{C}$}

Contamos con una fuente de africana de cocina Hayes 181C (NIM 0632), de perfil sencillo, borde con labio redondeado y pared cóncava de base plana; la pasta presenta un color característico anaranjado-claro con desgrasantes blancos (Fig. 9, n. ${ }^{\circ}$ 1) (Hayes, 1972). Esta tipología presenta generalmente perfiles similares a las fuentes de engobe rojo pompeyano, de sección más gruesa y con una acanaladura más marcada en el arranque de la pared, distanciándose así de las variantes más estilizadas de estas fuentes Hayes 181 (Huguet, 2009: 87).
Es bien sabido que gracias al trabajo de $\mathrm{M}$. Bonifay (2004: 213-214) las producciones africanas son unas de las mejores estudiadas y documentadas. Éste clasifica las tipologías de cocina según su lugar de origen, identificando tres zonas productivas de las cuales es la categoría B la que incluye esta fuente, que engloba todas aquellas producciones de la costa norte y oriental de Túnez, entre Sfax y Sousse, donde se comienzan a elaborar entre finales del s. II e inicios del III d.C.

Esta fuente es una pieza frecuente en contextos del s. III d.C. que nos obliga a centrarnos en zonas cercanas a Valencia, como el conjunto doméstico de Cartagena, en la C/ Cuatro Santos n. ${ }^{\circ} 40$, o en La Vallaeta, donde destaca la similitud de sus perfiles con los de engobe rojo pompeyano (Quevedo y Bermejo, 2012: 114, 125; Huguet, 2016: 315, 446). También la hallamos en la ciudad de Edeta (Llíria) en contextos de época de los Severos (Escrivà et al., 2014: 250).

En la ciudad de Valentia las intervenciones de la pl. del Negret n. ${ }^{\circ} 2-\mathrm{C} /$ Calatrava . $^{\circ} 10$ (finales s. II, principios del III d.C.), así como en el conjunto cerámico de la C/ del Mar (segunda mitad s. III d.C.), y las tres fosas del ustrinum de la necrópolis de La Boatella, son ejemplos de que es una forma que arranca a finales del II, aunque lo más frecuente será hallarla a lo largo de todo el s. III d.C. (Huguet, 2016: 183-184, 242-246, $315,454-455)$.

\subsubsection{Jarrita de TSA A Hayes 160}

En la única tumba seleccionada de la intervención realizada en la C/ Virgen de la Misericordia (Tumba 72) nos encontramos con una interesante Jarrita de TSA A Hayes 160 (Atlante, tav. XXI, 9/Lamboglia 11), una de las pocas piezas de cerámica de mesa con las que contamos (Carandini y Tortorella, 1981: 46-47). Tiene un cuerpo de forma doble convexa, siendo la parte superior más pequeña que la inferior; cuello alargado con acanaladuras, la parte inferior es plana y vertical, mientras que la media se contrae para rematar, en la zona superior, con una boca ligeramente abocinada. La base es plana con la moldura bastante alta, y un asa en forma de cinta que arranca de la zona inferior del cuello hasta el borde del hombro (Fig. 9, n. ${ }^{\circ}$ 6). En cuanto a su cronología, Hayes (1972: 189-190) la sitúa en época antoniniana y severiana, es decir, s. II y primer tercio del III d.C.

Lo característico de esta pieza es la elevada frecuencia con la que se ha documentado en espacios funerarios a lo largo de la zona valenciana e Ibiza. En Valentia se documentó en la pl. del Negret n. ${ }^{\circ} 2-\mathrm{C} /$ $\mathrm{n}^{\mathrm{o}}$ Calatrava n. ${ }^{\circ} 10$, también en Pollentia (Mallorca) y en la necrópolis de Can Fannals. En resumen, esta jarrita se ha hallado en prácticamente la totalidad de los contextos funerarios ibicencos del s. III d.C: Carrer

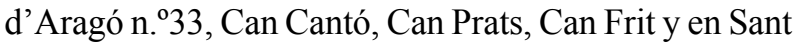
Antoni de Portmany, y es que además parece haber 

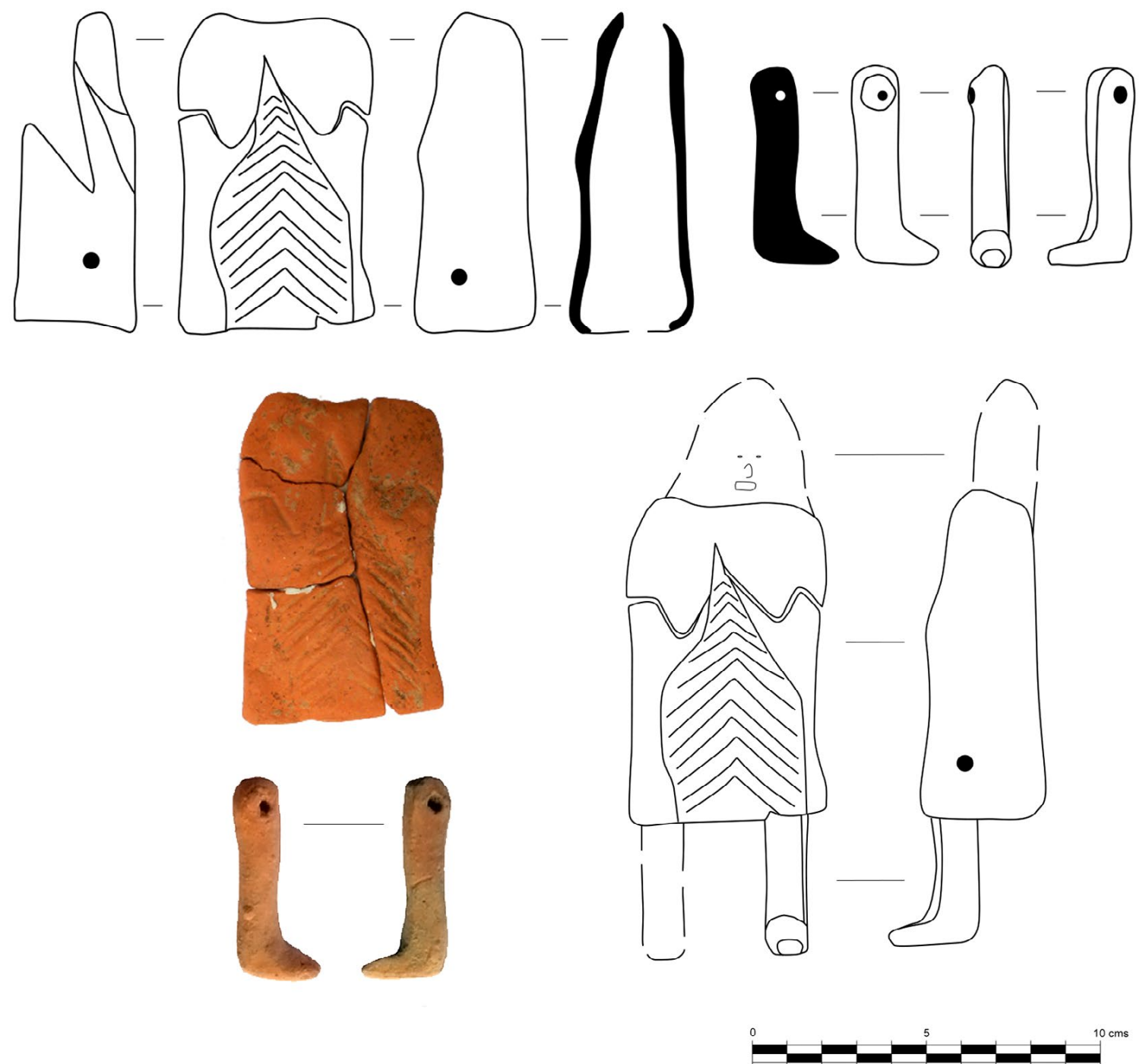

Figura 8: Posible Tintinnabulum de terracota formado por un torso con decoración vegetal (n. $\left.{ }^{\circ} 1331-2\right)$ y una pierna izquierda (n. ${ }^{\circ}$ 1331-1). Editado a partir de Huguet, 2016.

sido objeto de imitaciones locales en la isla (Caballero, 1966: 145-146; Hayes, 1972: 189-190; Vizcaíno, 2009: 581; Járrega, 2014a: 99).

En el levante peninsular el panorama no cambia demasiado, con casos documentados en la villa gerundense de Tolegassos; en cinco inhumaciones en la $\mathrm{C} /$ Hospital - pl. de San Agustí (Barcelona) (Beltrán de Heredia, 2007); en la villa romana de Antigons (Reus) y en la C/Cuatro Santos de Cartagena, ambas en contextos de los Severos (Járrega, 2014a: 88, 97-98; 2014b: 67-68; Quevedo y Bermejo, 2012: 125).

La progresiva desaparición de los ajuares funerarios a partir del s. II d.C., así como la preeminencia de las cerámicas comunes, proporcionan una excepcionalidad a esta pieza, que parece que no deja lugar a dudas sobre su cronología. Así mismo, también sería interesante ahondar en sus aspectos rituales y en el vínculo que pudiera tener con el mundo funerario, donde, como hemos podido ver, cuenta con una importante presencia.

\subsubsection{Terracota figurada (Tintinnabulum)}

En la Tumba 10 de la $\mathrm{C} /$ Palomar nos encontramos con dos interesantes fragmentos de terracota que parecen identificarse con un posible tintinnabulum. Por un lado, tenemos un elemento rectangular de cerámica común de cocción oxidante (n. $\left.{ }^{\circ} 1331-2\right)$ que presenta cuatro caras: la posterior es lisa y está mal conservada; las laterales, también lisas, presentan una perforación circular en la zona inferior; mientras que la delantera contiene un dibujo inciso precocción que posiblemente se corresponda con motivos vegetales. El otro fragmento de terracota se trata de una pierna $\left(\right.$ n. $^{\circ}$ 1331-1) de pequeñas dimensiones y representación esquemática: carencia de detalles anatómicos en el pie, la rodilla o el tobillo; también presenta un orificio en la parte superior, donde habría de unirse al resto del cuerpo (Fig. 8).

En el momento de la excavación se identificó como un exvoto procedente de alguna práctica votiva relacionada con la necrópolis, ya que se conocen conjuntos 
votivos con representaciones parciales de cuerpos, cuya finalidad era que el dios las cuidara o sanara (exvotos anatómicos). También cabría la posibilidad de que se tratase de una terracota figurada o un muñeco, muy comunes en ambientes funerarios. Dicho esto, actualmente se considera que estos fragmentos debieron pertenecer a un tintinnabulum, sigillum o cucullatus, en el que el cuerpo y brazos estaban cubiertos por una túnica decorada con motivos vegetales, y las extremidades inferiores debían de sujetarse mediante los orificios con una cuerda o hilo (Vaquerizo, 2002-2003; Huguet, 2016: 527-528).

Los sigilla son estatuillas zoomorfas o antropomorfas destinadas a contextos sacros que se han asociado con las divinidades denominadas cucullati o encapuchados, debido a sus vestimentas, y que se identifican con genios protectores (Salido y Rodríguez, 2015).

En cuanto a los tintinnabula, se identifican con el sexo masculino, y a menudo, con representaciones fálicas (Blázquez, 1984-1985); no obstante, también se conocen representaciones femeninas como el hallado en la $\mathrm{C} /$ Cavallers n. ${ }^{\circ} 26$ de Valencia, de gran similitud con este documentado en la necrópolis occidental, y también hallado en un contexto funerario probablemente del s. III d.C. (Huguet, 2016: 528).

Así pues, teniendo en cuenta los criterios estratigráficos de la excavación, junto con los hallazgos monetales y cerámicos, además del paralelo en la $\mathrm{C}$ / Cavallers, podemos situar el enterramiento entre finales del s. II y principios del III d.C.

\subsubsection{Lucerna Deneauve VII A/Dressel 20}

Otras de las piezas son dos lucernas Deneauve VII A/ Dressel 20, cuya cronología es tan extensa y el tipo tan recurrente que no nos puede proporcionar datos determinantes. Se trata de una forma muy frecuente en toda clase de contextos, entre los que se incluye los funerarios; por ello es más que probable la existencia de talleres en Hispania que la produjeran. Así lo atestiguan los rasgos decorativos y las marcas de taller documentadas en Bracara Augusta (destacando las del alfarero local Lucretius) (Morillo y Rodríguez Martín, 2008: 412-413; Morais, 2012; Huguet, 2016).

La primera lucerna (NIM 0661), de producción africana, cuenta con un delfín decorando el disco; este tipo iconográfico será el más representado de los animales marinos, asociándose con divinidades acuáticas como puede ser Poseidón o Taras (Fig. 9, n. ${ }^{\circ} 3$ ) (Deneauve 1969: P1. LXXIII-LXXIV; Amante, 1988: 219).

La otra lucerna (NIM 0659) no ha podido localizarse para su estudio debido a los trabajos de reorganización que se están llevando a cabo actualmente en el SIAM y que han impedido por lo tanto complementar la información con la que ya contábamos, procedente del informe de excavación y de la tesis de E. GarcíaPrósper (2015) (Fig. 7, n. ${ }^{\circ}$ 1).

Pese a que lo más común es situar esta tipología en contextos del s. II, esta puede oscilar desde mediados del s. I hasta principios del III d.C., una horquilla cronológica demasiado extensa como para aportar una datación precisa de las respectivas tumbas.

\subsubsection{Copa de TSA A Hayes 8A}

Contamos también con una copa de TSA A Hayes 8A (NIM 0650). Se trata de una copa carenada, de borde redondeado, labio pronunciado al exterior y moldura al interior y con decoración a ruedecilla en el labio y la carena (Fig. 9, n. ${ }^{\circ}$ 4); esta forma deriva de la Dragendorff 29 en T.S. Sudgálica (Hayes, 1972: 32-35).

La cronología de esta copa abarca desde finales del s. I hasta la segunda mitad del s. II d.C., aunque posiblemente llegue hasta principios del s. III. Lo cierto es que se trata de una de las formas tempranas de sigillata africana, de época Flavia; por ello, lo más frecuente será hallarla en contextos de finales del s. I d.C., y a lo largo de todo el s. II, como atestiguan algunas tumbas de Ischia, Tipasa, Lipari, Albintimilium o Pupput (Nieto, 1993; Bonifay, 2004: 156).

\subsubsection{Jarra-biberón Isings 99}

En la tumba anteriormente mencionada se halló una jarra-biberón Isings 99 (NIM 0651). Está realizada por soplado, con panza esférica o globular con cuello alto de embudo, base plana, asa y un pequeño pico vertedor cónico (Fig. 9, n. ${ }^{\circ}$ 5). Se halla en buen estado de conservación, preservando el perfil prácticamente en su totalidad exceptuando el asa y el cuello (Isings, 1957: 118).

Es frecuente documentar estas jarritas en contextos funerarios, como en las necrópolis de Cany o Sens; o en la Península Ibérica, como en la necrópolis de Marismilla/Campo de Futbol (Riotinto, Huelva), donde apareció junto con una Isings 93, de similar cronología (Pérez Macías et al., 2012: 63, 76). También tenemos otro ejemplar en la Tumba 1 de la villa de El Vergel (San Pedro del Arroyo, Ávila), datándose el conjunto desde la segunda mitad del s. III al IV d.C. (Moreda Blanco et al., 2010-2011: 143, 153).

Es importante resaltar que se documentó en el interior de la anteriormente mencionada copa de TSA A Hayes 8A; ambas piezas constituyen este ajuar funerario (UE 2294) que por la jarra-biberón Isings 99 no podemos situar en una fecha anterior al s. III d.C. 

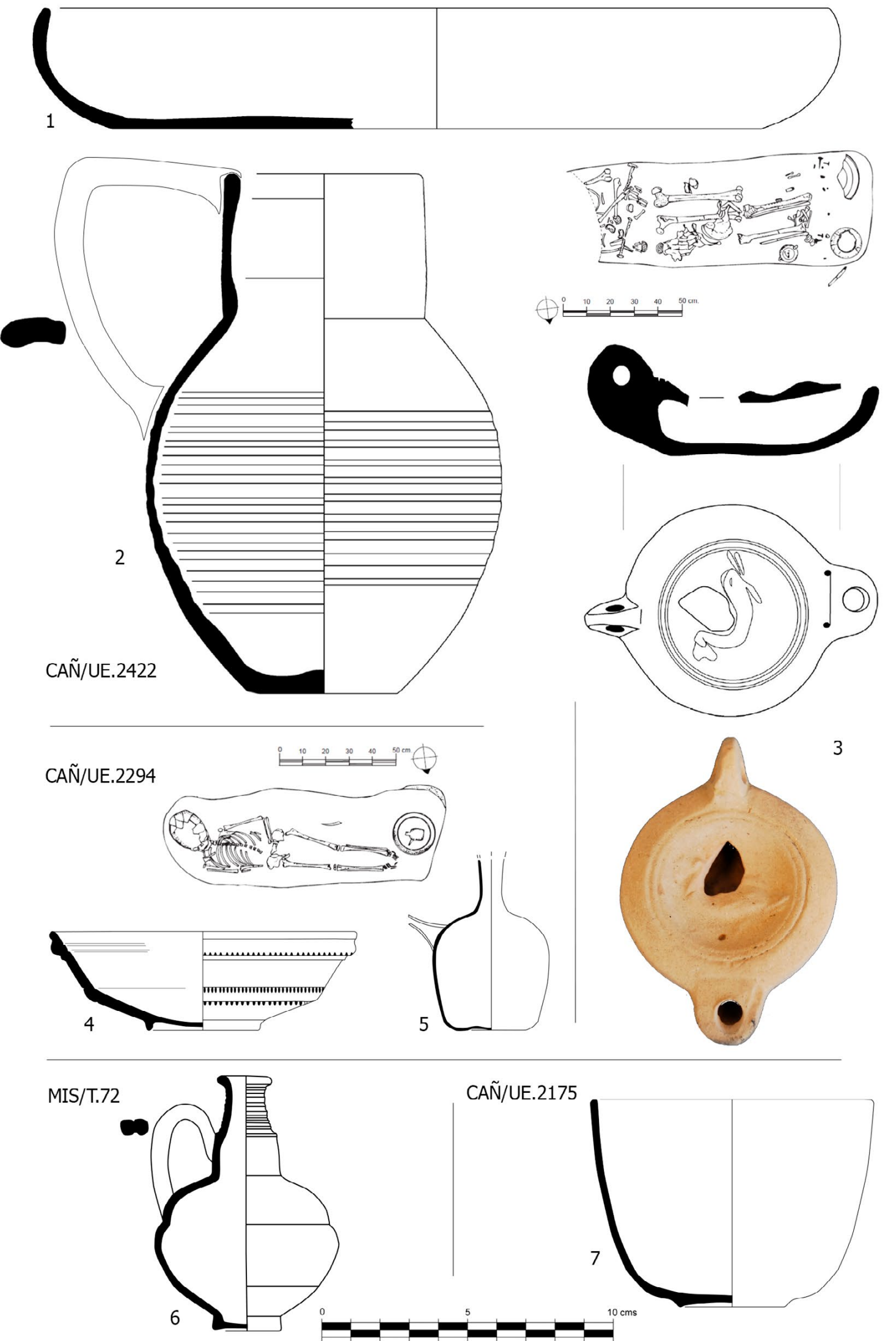

Figura 9: Enterramientos y ajuares de la necrópolis occidental: 1.- Fuente africana de cocina, Hayes 181C (NIM 0632); 2.- Jarrita africana Bonifay 50/Tolegassos 489-490 (NIM 0631); 3.- Lucerna Dressel 20 con delfín en disco (NIM 0661); 4.- Copa de TSA A, Hayes 8A (NIM 0650); 5.- Jarra-biberón de vidrio Isings 99 (NIM 0651); 6.- Jarrita de TSA A, Hayes 160; 7.- Cubilete de paredes finas tipo «cáscara de huevo», Mayet XXXVI B (NIM 0663). Editado a partir de García-Prósper (2015), Huguet (2016) y Rosselló y Ruiz Val (1996a); 7, elaboración propia. 


\section{OTROS POSIBLES ENTERRAMIENTOS DEL S. III D.C.}

Finalmente, vemos importante mencionar otros enterramientos que posiblemente pertenezcan a la última fase de la necrópolis occidental, sin embargo, hemos decidido separar estos ajuares de los anteriormente comentados por la problemática que supone vincular algunas de estas producciones al momento de abandono de la necrópolis.

Uno de los enterramientos de la intervención de la C/ Cañete-Quart (UE 2175) cuenta con un ajuar compuesto por un cubilete de paredes finas de la producción denominada «cáscara de huevo» (NIM 0663) (Fig. 9, n. $\left.{ }^{\circ} 7\right)$. Se trata de una Mayet XXXIV B que destaca por la extrema delgadez de sus paredes, de pasta blanquecina y engobe gris claro (Mayet, 1975: 69-71, 150). La cronología de esta pieza se sitúa en el s. I d.C., entre los gobiernos de Tiberio y Vespasiano, es decir, bastante alejado del período que estamos tratando, no obstante, apareció junto a un as de Antonino Pio de la segunda mitad del s. II d.C.

Su producción está bien estudiada y constatada; lo interesante es su difusión, teniendo especial importancia las producciones béticas en lo que se refiere a la costa mediterránea occidental, desde el norte de África a la península Itálica, donde el número de estas formas es menor, siendo más relevante en los principales puertos comerciales como Ostia o Pompeya.

En cuanto al centro productor, se ha planteado la zona de Cádiz teniendo como principal evidencia los restos del pecio Port-Vendres II con importantes vestigios que han supuesto un avance en el estudio de la economía bética y del comercio desde el sur de Hispania. Sin embargo, en la zona interior y oriental de la península hemos de tener en cuenta la influencia del taller de Rubielos de Mora (Teruel), cuya producción acapara el mercado, siendo numerosa la documentación de estas formas desde la zona del valle del Ebro hasta Sagunto y Cartagena. No debemos obviar el hecho de que en el sur de Hispania es donde se hallaban los talleres más importantes de esta producción de «cáscara de huevo», donde se han documentado abundantemente coincidiendo con el esplendor de Baelo, pese a que no se conocen hornos (Remesal, 1979: 379-380; Passelac, 1993a: 519; López Mullor, 2008: 367-368; Melchor y Benedito, 2009: 237-236).

Es importante recalcar la especial difusión de las producciones de este taller en la zona saguntina, lo que se podría conectar con las hipótesis de algunos investigadores en la relación de las producciones del taller turolense con los llamados «vasos saguntinos» de lo que hablan algunos autores clásicos (Peñil Mínguez et al., 1985-1986: 190-197). Cronológicamente, estas producciones se vienen fechando entre el imperio de Tiberio y la época Flavia, aunque se han documentado casos en los que se extienden hasta finales del s. I, principios del II e incluso III d.C. En este caso, contamos con multitud de paralelos de finales del s. I e inicios del
II: la colonia Celsa (finales s. I d.C.), la villa romana de La Vallaeta (finales s. I d.C.), la villa romana de Els Ametllers (inicios s. II d.C.) o el vertedero de la pl. del Negret n. ${ }^{\circ} 2-\mathrm{C} /$ Calatrava n. ${ }^{\circ} 10$ (s. II d.C.); siendo menos habituales ejemplos del s. III, como el yacimiento de Julióbriga (Cantabria) o la UAIII de los Baños del Almirante en Valencia (época de los severos) (López Mullor et al., 2001: 66, 101, 108, 120-124; Huguet, 2009: 77-80; Mínguez, 2009: 460-463).

Esta es una forma frecuentemente documentada en contextos funerarios valencianos, aunque la mayoría nos remiten a los ss. I-II como es el caso de un monumento funerario del solar de la pl. de la Morería (Sagunto), en una intervención realizada al norte del Turia (Valencia), en la C/ Pepita n. ${ }^{\circ}$ 27; también está presente en las necrópolis de Puig des Molins (Ibiza), «Sa Carrotxa» (Mallorca), Ampurias, Tipasa (Argelia), así como en la de Baelo, donde la existencia de estos posibles talleres béticos nos dejan multitud de hallazgos en los enterramientos de los ss. I-II d.C. en el conventus gaditanus (De Miquel, 1986: 11-112; Vargas, 2002: 301-302; Melchor y Benedito, 2009: 237, 243245; Huguet, 2016: 253-254).

En resumen, lo más probable es que estemos ante un tipo cuya producción debemos situarla en la zona sur-oriental de Teruel, concretamente en el taller de Rubielos de Mora, cuyas pastas blanquecinas con engobes grises claros o sepias recuerdan al ejemplar estudiado; sin embargo, no debemos obviar la posibilidad de que se tratase de una producción de carácter regional, como imitación a los elaborados en el taller turolense (Martín y Rodríguez, 2008).

Así pues, estamos ante una pieza que hemos de enmarcar en torno a los ss. I-II, aunque en el caso de la necrópolis occidental, se halló como parte del ajuar del enterramiento UE 2175 en el que también se documentó un as de tiempos del emperador Antonino Pio (Gozalbes, 1997), fechado entre los años 148 y 161 d.C. (RIC III, 1171. Mattingly y Sydenham, 1930: 167). Contamos con otro ejemplo similar procedente de la Tumba 10 de la intervención de la C/ Palomar, donde se halló un as de Faustina I acuñada durante el gobierno del emperador Antonino Pío junto a una sartén de la llamada producción de engobe rojo pompeyano, de cronología muy anterior (s. II-I a.C.) aunque perduren algunas formas más tardías hasta el s. I, e incluso minoritariamente, hasta el II d.C. (Passelac, 1993b; Pascual, 2012: 43, 49).

Pese a que normalmente la utilización de una moneda como ajuar pueda implicar que esta ha sufrido un acusado desgaste o está en desuso, estos hallazgos monetales comentados no parecen tener un relevante desgaste, lo que sitúa estos enterramientos en la segunda mitad del s. II d.C. pese a la excepcionalidad de encontrarnos en los ajuares con producciones de paredes finas o engobe rojo pompeyano, ambas de cronología muy anterior.

De la intervención en la C/Virgen de la Misericordia, también hemos considerado importante mencionar el 
hallazgo de un fragmento indeterminado de TSA D en una gran fosa circular (UE 1514). Esta producción puede datarse entre finales del s. III y principios del IV, hasta finales del VI d.C., por lo que se alejaría demasiado del momento en el que planteamos que se produjo el abandono de la necrópolis (Raynaud, 1993).

Esta gran fosa contenía un gran paquete de restos cerámicos de campaniense A y $\mathrm{B}$, TSH y TSG, además del mencionado fragmento de TSA D, todas de cronologías muy dispares entre sí: las producciones campanienses están en torno a los ss. III-I a.C., la TSH y TSG entre los ss. I y II d.C. y la TSA D desde el s. III al VI d.C.

Se ha planteado la posibilidad de que esta sea una fosa de expolio del s. IV d.C., y se ha puesto en relación con transformaciones sociales y políticas que se vivieron en la ciudad de Valentia. Lo que sabemos con seguridad es que estamos ante una fosa con material revuelto que abarca una horquilla cronológica de hasta nueve siglos (Rosselló, 1993: 22-23; Rosselló y Ruiz Val, 1996a: 159, 162, 164; 1996b: 190-192; fichas UUEE).

Como venimos diciendo, la escasez o ausencia de ajuar en las tumbas más tardías proporcionan cierta relevancia al hallazgo de un fragmento de cerámica TSA C Hayes 50 en la zanja de construcción de una de las tumbas de la C/ Virgen de la Misericordia, en las UE 1230 y UE 1242, ambas pertenecientes al mismo estrato y que nos proporcionaría una fecha post quem de las tumbas más tardías. Si bien existe la posibilidad de que fuese una intrusión, hemos visto importante mencionar este hallazgo, ya que es una de las piezas que permitieron establecer el momento de abandono en esta primera intervención y que actualmente sigue vigente debido a la ausencia del estudio del material, así como de la puesta en común de toda la documentación procedente del resto de intervenciones realizadas con posterioridad (Rosselló y Ruiz Val, 1996a: 163-164).

Se trata de un plato de gran tamaño, de base plana con un minúsculo pie, la pared se alza recta en ángulo abierto con respecto a la base. El labio es redondeado o biselado según la variante del tipo. Las paredes son delgadas y sin decoración. Tiene gran similitud con la forma Hayes 31 en TSA A, de la que posiblemente derive (Hayes, 1972: 53, 68-69, 73).

Tras consultar las fichas de unidad estratigráfica parece ser que no se trata de una intrusión (fichas UUEE). Es una de las producciones más comunes de TSA C, por lo que el marco cronológico está bien constatado, yendo desde mediados del s. III hasta finales del IV, aunque no será extraño encontrarlo en contextos del V d.C.

\section{VALORACIÓN GENERAL}

La novedad del trabajo reside en la revisión de todos aquellos ajuares, principalmente cerámicos, de las tumbas más tardías; para ello, hemos tenido acceso, a través del SIAM, a multitud de documentación inédita procedente de informes, memorias, fichas de unidad estratigráfica, así como de material fotográfico y planimetrías de las diversas intervenciones realizadas en la zona de la necrópolis occidental de Valentia.

El motivo que nos ha impulsado a poner en común toda la información y el material de estas intervenciones y reexaminar los ajuares es arrojar luz al momento de abandono de la necrópolis; también tenemos el objetivo de reducir la disparidad entre el desconocimiento de la última fase y la abundante investigación de las fases iníciales de este espacio funerario (s. II a.C.- I d.C.), pues prácticamente la totalidad de estas tumbas presentan ajuar y por lo tanto, aportan mucha más información.

En el trascurso de las cinco intervenciones realizadas en este espacio funerario hemos visto cómo en los diversos informes y memorias de excavación se ha ido reajustando la fecha de abandono, que en un principio se sitúo laxamente desde finales del s. II hasta el s. IV, mientras que más recientemente se consideraba que el abandono se produjo en los ss. II-III d.C.

La revisión de toda esta documentación también nos ha permitido conocer el criterio utilizado en esas intervenciones para fijar estas cronologías. La realidad es que la ausencia de material en las tumbas más tardías, así como el complejo entramado de hasta cinco enterramientos superpuestos, han dificultado esta labor enormemente.

Así pues, la cronología de abandono fijada en las primeras intervenciones (finales del s. II hasta el s. III-IV) se fundamentaba en dos hallazgos puntuales de fragmentos de TSA C (Hayes 50) y TSAD (Rosselló, 1993; Rosselló y Ruiz Val, 1996b), sin embargo, actualmente, y tras la revisión de la documentación arqueológica, consideramos demasiado vagos estos hallazgos como para que sean cronológicamente tan determinantes. Mientras que en las recientes investigaciones se mantienen más escépticos, ya que la existencia de gran cantidad de tumbas sin ajuar les hicieron optar acertadamente por fijar una cronología abierta, situándose el momento de abandono en el s. II-III d.C.; esta cronología se fundamenta en los escasos hallazgos monetales y cerámicos de los ajuares más tardíos, que datan del s. II, pues no incidieron en aquellas formas en cerámica común que nos remiten al s. III d.C.

El tipo de hallazgos en los ajuares se corresponde con las formas que encontramos habitualmente en contextos funerarios: lucernas, con un marcado carácter simbólico-religioso, en el que la luz proporcionaba al difunto la iluminación necesaria para la vida en el más allá; también jarras o formas cerradas utilizadas como contenedoras de líquidos o como urnas cinerarias; finalmente, elementos de consumo como cuencos y copas que contendrían los alimentos necesarios para el difunto.

En cuanto a las producciones, es importante destacar la frecuencia de las formas en cerámica común, y en menor cantidad, de las sigillatas africanas. Esto sucede 


\begin{tabular}{|c|c|c|c|}
\hline $\begin{array}{l}\text { Inhumación/ } \\
\text { Cremación }\end{array}$ & Ajuares & Cronología & $\begin{array}{c}\text { Cronología del ente- } \\
\text { rramiento }\end{array}$ \\
\hline \multirow{2}{*}{ UE 2156} & Olpe Gr. I.2 Urceus (NIM 0614) & Mitad s. III d.C. & \multirow{2}{*}{ Mitad s. III d.C. } \\
\hline & Trulla (NIM 0615) & S. II-III d.C. & \\
\hline \multirow{3}{*}{ UE 2422} & Lucerna africana Dressel 20 (NIM 0661) & Mitad s. I - ppios. III d.C. & \multirow{3}{*}{ S. III d.C. } \\
\hline & $\begin{array}{l}\text { Olpe Bonifay } 50 \text { / Tolegassos 489-490 (NIM } \\
\text { 0631) }\end{array}$ & S. III d.C. & \\
\hline & $\begin{array}{l}\text { Fuente africana de cocina Hayes 181C (NIM } \\
0632 \text { ) }\end{array}$ & Finales s. II - ppios. III d.C. & \\
\hline \multirow{3}{*}{ UE 2183} & Cuencos Gr. III Calix (NIM 0628-0629) & S. III d.C. & \multirow{3}{*}{ Mitad s. III d.C. } \\
\hline & Lucerna Dressel 20 (NIM 0659) & Mitad s. I - ppios. III d.C. & \\
\hline & Olpe Gr. I.2 Urceus (NIM 0616) & Mitad s. III d.C. & \\
\hline UE 2053 & Olpe Gr. I.2 Urceus (NIM 0654) & Mitad s. III d.C. & Mitad s. III d.C. \\
\hline UE 2322 & Olpe Gr. I.2 Urceus (NIM 0621) & Mitad s. III d.C. & Mitad s. III d.C. \\
\hline UE 2255 & Olpe Gr. I.2 Urceus (NIM 0633) & Mitad s. III d.C. & Mitad s. III d.C. \\
\hline \multirow{2}{*}{ UE 2294} & Copa de TSA A Hayes 8A (NIM 0650) & S. II d.C. & \multirow{2}{*}{ S. III d.C. } \\
\hline & Jarra-biberón Isings 99 (NIM 0651) & S. III d.C. & \\
\hline \multirow[t]{2}{*}{ UE 2175} & $\begin{array}{l}\text { Cubilete de paredes finas «cáscara de huevo» } \\
\text { Mayet XXXIV B (NIM 0663) }\end{array}$ & S. I - mitad s. II d.C. & \multirow{2}{*}{$\begin{array}{c}\text { Segunda mitad s. II } \\
\text { d.C. }\end{array}$} \\
\hline & As de Antonino Pio & 148-161 d.C. & \\
\hline TUMBA 72 & Jarrita de TSA A Hayes 160 & $\begin{array}{l}\text { S. II - primer tercio del III } \\
\text { d.C. }\end{array}$ & $\begin{array}{l}\text { Finales s. II - ppios. } \\
\text { III d.C. }\end{array}$ \\
\hline \multirow{2}{*}{ TUMBA 10} & Tintinnabulum (n. $\left..^{\circ} 1331-1 / 2\right)$ & S. II-III d.C. & \multirow{2}{*}{$\begin{array}{l}\text { Segunda mitad s. II - } \\
\text { ppios. III d.C. }\end{array}$} \\
\hline & As de Diva Faustina & Segunda mitad s. II d.C. & \\
\hline
\end{tabular}

Figura 10: Tabla-resumen con la propuesta cronológica para cada uno de los enterramientos y ajuares estudiados.

como consecuencia del auge de las producciones en cerámica común local/regional, que copian las formas de vajilla de mesa; además, debemos valorar el apogeo del comercio marítimo africano, cuyas producciones en este momento ya se extienden a lo largo de todo el Imperio.

Como podemos observar en la tabla-resumen (Fig. 10) del conjunto de piezas que forman estos ajuares es determinante la presencia de la cerámica común. Se trata de jarras y cuencos, posiblemente de producción local/regional, de morfología avanzada que se encuentran correctamente referenciados y constatados en la ciudad de Valentia gracias al trabajo de E. Huguet (2016).

La forma más característica son los urcei, cuya buena conservación nos ha permitido apreciar adecuadamente la evolución morfológica que caracteriza a estas jarritas de mediados del s. III d.C.: observamos cómo van reduciendo su tamaño considerablemente con respecto a los olpes de siglos anteriores; la panza se va volviendo más esférica y desciende hasta la parte inferior del cuerpo; en cuanto al labio, se redondea y se suaviza en contraposición a los bordes mucho más marcados y quebrados de sus predecesores; finalmente pierde una de las asas y se reduce ligeramente su tamaño, y la sección va adquiriendo forma de cinta.

De las piezas en sigillata africana A destaca la jarrita Hayes 160 y la relación que parece tener esta forma con el mundo funerario ibicenco y valenciano del s. II e inicios del III d.C. según atestiguan los paralelos. Ante la escasez de material vemos importante reflexionar sobre aquellas producciones que no se han hallado en estas tumbas tardías, ejemplo de ello es la sigillata africana C, la cual comienza en el 230/240 aprox. por lo que su presencia sería determinante para asegurar una cronología del s. III d.C. Es precisamente la ausencia de esta producción la que podría indicar que el momento de abandono se sitúa en época severiana; sin embargo, su ausencia también estaría justificada pues en las tumbas tardías las formas de vajilla de mesa no son demasiado abundantes, como tampoco lo son realmente los ajuares.

En cuanto a los hallazgos monetarios vemos cómo la gran mayoría pertenecen al período comprendido entre época augústea y finales del s. II d.C., el que sería el momento de mayor actividad de la necrópolis. En este sentido es significativa la ausencia de monedas del s. III (o posteriores), lo que podría estar indicando el momento de abandono de la necrópolis; no obstante, aunque estos hallazgos monetales pueden ser determinantes, en el caso de la última fase de la necrópolis occidental no son relevantes, por lo que hemos de apoyarnos en el estudio de los materiales, así como en los planteamientos arqueológicos (Gozalbes, 1997).

Otra cuestión que hemos de abordar es por qué se desacraliza un cementerio de tal envergadura y magnitud; realmente, sin una razón de peso es inusual que esto suceda a no ser que lo pongamos en relación con 
las profundas e importantes transformaciones sociales, políticas, económicas y urbanísticas que vive el Imperio romano al final del período Severo. La crisis del s. III d.C. afecta también profundamente a la ciudad de Valentia, donde se produce el abandono de importantes zonas y edificios, así como una consecuente reducción del perímetro urbano, produciéndose un repliegue de la ciudad hacia el sureste y convirtiendo la ciudad en un campo de ruinas, lo que repercutiría también en los espacios funerarios (Machancoses, 2015).

Así pues, hemos de enmarcar el abandono de la necrópolis occidental, como constata el estudio cerámico, en época Severa, momento en el que cobraría protagonismo un nuevo espacio sacro, más cercano al nuevo núcleo urbano (próxima a la Vía Augusta), la necrópolis de La Boatella (Soriano, 1989). También contamos con la necrópolis hallada en el Portal de Ruzafa, con enterramientos del s. III d.C. y material similar a los expuestos en este trabajo, sin embargo, carecemos de datos arqueológicos que nos permitan determinar su período de vigencia (Machancoses, 2015: 593).

\section{REFERENCIAS}

Amante Sánchez, M. (1988). Representaciones iconográficas en las lucernas romanas de la región de Murcia. Antigüedad y cristianismo, $V, 213-254$. Recuperado de: http://revistas. um.es/ayc/article/view/60161

Beltrán de Heredia Bercero, J. (2007). La Via Sepulchralis de la plaza Vila de Madrid. Un ejemplo del ritual funerario durante el Alto Imperio en la necrópolis occidental de Barcino. QUARHIS, Época II, 3, 6-57.

Blázquez Martínez, J. M. (1984-1985). Tintinnabula de Mérida y de Sasamón (Burgos). Zephyrus, 37-38, 331-335. Recuperado de: http://revistas.usal.es/index.php/0514-7336/ article/view/7804

Bonet, H. y Mata, C. (2008). Las cerámicas ibéricas. Estado de la cuestión. En D. Bernal Casasola y A. Ribera i Lacomba (Eds.). Cerámicas hispanorromanas, un estado de la cuestión (pp.147-170). Cádiz: Universidad de Cádiz.

Bonifay, M. (2004). Études sur la céramique romaine tardive d'Afrique. Oxford: British Archaeological Reports.

Bustamante Álvarez, M. (2012). Las cerámicas comunes altoimperiales de Augusta Emerita. En D. Bernal Casasola y A. Ribera i Lacomba (Eds.). Cerámicas hispanorromanas II: Producciones regionales (pp.407-433). Cádiz: Universidad de Cádiz. Recuperado de: http://hdl.handle.net/10261/138266

Caballero Zoreda, L. (1966). Estado actual del estudio de la cerámica sigillata clara en el Mediterráneo occidental. Empúries, 28, 139-156. Recuperado de: http://hdl.handle. net/10261/27376

Carandini, A. y Tortorella, S. (1981). Produzione A. En A. Carandini (Ed.). Atlante delle forme ceramiche I. Ceramica fine romana nel bacino mediterraneo (medio e tardo Impero), Enciclopedia dell'Arte Antica Classica e Orientale (pp.1951). Roma: Istituto della Enciclopedia Italiana.
Casas, J., Castanyer, P., Nolla, J. M. y Tremoleda, J. (1990). Ceràmiques comunes $i$ de producció local d'època romana. I. Materials augustals i alto-imperials a les comarques orientals de Girona. Sèrie Monogràfica, 12. Girona: Centre Investigacions Arqueològiques de Girona.

Chofre Navarrete, M. L. (1995). Trulla/cazo de Júpiter hallado en el faro de Cullera (Valencia). Saguntum, 28, 265272. Recuperado de: http://ojs.uv.es/index.php/saguntum/ article/view/2168

Deneauve, J. (1969). Lampes de Carthage. Paris: CNRS.

Escrivà, V. (1995). Cerámica común romana del Municipium Liria Edetanorum. Nuevas aportaciones al estudio de la cerámica altoimperial en la Hispania Tarraconensis. Monografias Emporitanes, 8, 167-186.

Escrivà, V., Martínez, C. y Vidal, X. (2014). Contextos cerámicos, desarrollo urbano y abandono del municipio romano de Edeta (Llíria, Valencia). S. III-IV d.C. En S. F. Ramallo Asensio y A. Quevedo Sánchez (Coords.). Las ciudades de la Tarraconense oriental entre los s. II-IV d.C., evolución urbanística y contextos materiales (pp.245-273). Murcia: Universidad de Murcia.

Ettlinger, E., Hedinger, B, Hoffman, B., Kenrick, P. M., Pucci, G., Roth-Rubi, K.,... y Zabehlicky-Schffenegger, S. (1990). Conspectus Formarum Terrae Sigillatae Italico Modo Confectae. Bonn: Rudolf Hubelt.

García-Bellido, A. (1966). Las trullae argénteas de Tiermes. Archivo Español de Arqueología, 39, 113-123. Recuperado de: http://www.cervantesvirtual.com/obra/ las-trullae-argnteas-de-tiermes-0/

García-Prósper, E. (2000). Memoria de excavación de la C/ Cañete-Quart $n{ }^{\circ} 4$ (5CAÑ004). (Memoria de excavación). Ajuntament de València. Archivo SIAM (Valencia).

García-Prósper, E. (2015). Los ritos funerarios de la necrópolis romana de la calle Quart de Valencia (siglos II a.C-III d.C). (Tesis Doctoral). Universitat de València. València. Recuperado de: http://roderic.uv.es/handle/10550/50746

García-Prósper, E. y Guérin, P. (1999). Memoria de excavación de la C/ Cañete-Quart n. ${ }^{\circ} 4$ (4CAÑO04). (Memoria de excavación). Ajuntament de València. Archivo SIAM (Valencia).

García-Prósper, E. y Polo Cerdá, M. (2003). Enterramientos en decúbito prono y un posible preso entre los primeros pobladores de Valencia (siglos II a.C.-III d.C.). En M. Campo y F. Robles (Eds.). ¿Dónde estamos?, Pasado, presente y futuro de la Paleopatología (pp.298-316). Madrid: Universidad Autónoma de Madrid. Recuperado de: http:// hdl.handle.net/10486/3264

García-Prósper, E., Polo Cerdá, M. y Guérin, P. (2003). Rituales funerarios ibéricos en la necrópolis fundacional de Valentia. Anales de Arqueología Cordobesa, 13-14, 279-310. Recuperado de: http://hdl.handle.net/10396/3580

García-Prósper, E., Polo Cerdá, M. y Guérin, P. (2007). Aproximación a la Arqueología funeraria de Valencia a través de la necrópolis de la calle Quart (ss. II a.C-III d.C): estudio preliminar de los rituales funerarios, bioantropología 
y paleopatología. En F. J. Barca y J. Jiménez Ávila (Eds.). Enfermedad, muerte y cultura en las sociedades del pasado. Importancia de la contextualización en los estudios paleopatológicos. Vol I. Actas del VIII Congreso Nacional de Paleopatología (Cáceres, 2005) (pp.159-187). Cáceres: Fundación Academia Europea de Yuste. Recuperado de: http://www.uam.es/otros/sepal/actas/actas files/trabajos/08 Caceres/16\%20Com.08.pdf

González Villaescusa, R. (2001). El mundo funerario romano en el País Valenciano monumentos funerarios y sepulturas entre los siglos I $a$. de C.-VII $d$. de C. Madrid-Alicante: Casa de Velázquez - Instituto Alicantino de Cultura «Juan Gil-Albert».

Gozalbes, M. (1997). Los hallazgos numismáticos de una necrópolis de Valentia (C/Virgen de la Misericordia). Anales de Arqueología cordobesa, 8, 197-212. Recuperado de: http:// hdl.handle.net/10396/2738

Hayes, J. W. (1972). Late Roman Pottery. London: The British School at Rome.

Huguet, E. (2009). Material cerámico de la villa romana de La Vallaeta M15.3. Arse, 43, 63-159. Recuperado de: http:// bddoc.csic.es:8080/ver/ISOC/docu/765981.html

Huguet, E. (2016). La ceràmica comuna de la ciutat romana de Valentia (Segles II $a E-I I I d E$ ). (Tesis doctoral). Universitat de València. València. Recuperado de: http:// roderic.uv.es/handle/10550/56163

Huguet, E., Ribera, A., Ruiz, E. y Salavert, J. V. (2008). Una zona alfarera del alto imperio al norte de Valentia. En Actes du Congrès de L'Escala-Empúries (Saint-Paul-TroisChâteaux, 2008) (pp.159-168). Marseille: Société Française d'Étude de la Céramique Antique en Gaule.

Isings, C. (1957). Román Glass from dated Finds. GroningenDjakarta: J.B. Wolters.

Járrega, R. (2014a). Les ceràmiques. Un exemple de l'activitat comercial a l'ager Tarraconensis. En R. Járrega y M. Prevosti (Eds.). Els Antigons, una vil-la senyorial de Camp de Tarragona (pp.55-193). Tarragona: Institut d'Estudis Catalans.

Járrega, R. (2014b). Revisión crono-tipológica de un grupo de cerámicas africanas de cocina: la forma Ostia I, 272. Atlante CVII, 11-12. Quaderns de Prehistòria i Arqueologia de Castelló, 32, 67-75.

López Gregoris, M. ${ }^{\mathrm{a}}$ R. (2005). El uso del diminutivo en el lenguaje técnico latino. Revista de Estudios Latinos (RELat), $5,75-96$.

López Mullor, A., Baldomà, M., Clua, M., Estany, I., Gumà, M., Martín, A.,... y Zucchitello, M. (2001). Les excavacions de 1985-1989 i 1992 a la Villa Romana dels Ametllers, Tossa (Selva). Barcelona: Patronat de la Villa Romana dels Ametllers.

López Mullor, A. (2008). Las cerámicas de paredes finas en la fachada mediterránea de la Península Ibérica y las Islas Baleares. En D. Bernal Casasola y A. Ribera i Lacomba (Eds.). Cerámicas hispanorromanas, un estado de la cuestión (pp.343-384). Cádiz: Universidad de Cádiz. Recuperado de: http://hdl.handle.net/10045/14425
Machancoses López, M. (2015). Topografía urbana de la Valentia romana altoimperial: ciudad y suburbio. (Tesis doctoral). Universitat de València. Valéncia. Recuperado de: http://roderic.uv.es/handle/10550/47947

Martín Hernández, E. y Rodríguez Martín, G. (2008). Paredes finas de Lusitania y del cuadrante noroccidental. En D. Bernal Casasola y A. Ribera i Lacomba (Eds.). Cerámicas hispanorromanas, un estado de la cuestión (pp.385-406). Cádiz: Universidad de Cádiz.

Martínez Pérez, M. A. (2016). La necrópolis de Orriols (Valencia): ejemplos de ritual funerario en época romana (siglo II-IV d.C.). Lucentum, $X X X V$, 171-191. DOI: http:// dx.doi.org/10.14198/LVCENTVM2016.35.09

Mattingly, H. y Sydenham, E. A. (1930). Roman Imperial Coinage Vol. 3: Antoninus Pius-Commodus. London: Spink \& Son.

Mayet, F (1975). Les Céramiques à parois fines dans la Péninsule Ibérique. París: Centre Pierre Paris.

Melchor, J. M. y Benedito, J. (2009). Estudio de las cerámicas romanas de paredes finas de la excavación del solar de la plaza de la Morería (Sagunto). Arse, 43, 231-248. Recuperado de: http://bddoc.csic.es:8080/ver/ISOC/docu/765985.html

Mínguez Morales, J. A. (2009). Las cerámicas de paredes finas en la Colonia Lepida/Celsa (Velilla de Ebro, Zaragoza). Su relación con el territorio aragonés. Zephyrus, 44, 457-470. Recuperado de: http://revistas.usal.es/index.php/0514-7336/ article/view/3410

Miquel Santed, L. E. (1986). Las cerámicas tipo «cáscara de huevo» en Cartagena. Anales de Prehistoria y Arqueología, 2, 103-118. Recuperado de: http://revistas.um.es/apa/article/ view/58571/56421

Morais, R. (2012). Las lucernas de producción regional de Bracara Augusta. En D. Bernal Casasola y A. Ribera i Lacomba (Eds.). Cerámicas hispanorromanas II: Producciones regionales (pp.369-394). Cádiz: Universidad de Cádiz.

Moreda Blanco, F. J., Vilar, S., Serrano, R. y Carral, R. (20102011). La necrópolis tardorromana de la villa de «El Vergel» (San Pedro del Arroyo, Ávila). Oppidum, 6-7, 141-184.

Morillo, A. y Rodríguez Martín, G. (2008). Lucernas hispanorromanas. En D. Bernal Casasola y A. Ribera i Lacomba (Eds.). Cerámicas hispanorromanas, un estado de la cuestión (pp.407-427). Cádiz: Universidad de Cádiz.

Nieto Prieto, J. (1993). De la Dragendorff 29 a la Hayes 8: consideraciones sobre el comercio marítimo en los siglos I y II d.C. Cypsela, 10, 77-85. Recuperado de: http://www.raco. cat/index.php/Cypsela/article/view/119160

Noguera Celdrán, J. M., Abascal Palazón, J. M. y Madrid Balanza, M. J. (2017). Un Titulus Pictus con titulatura imperial de Carthago Nova y puntualizaciones a la dinámica urbana de la ciudad a inicios del s. III d.C. Zephyrus, 79, 149172. DOI: https://doi.org/10.14201/zephyrus201779149172

Olcese, G. (1993). Ceramiche comuni di Albintimilium. Indagine archeologica e archeometrica sui materiali 
dell'area. Florencia: All'insegna del giglio-Consiglio nazionale delle ricerche.

Ortega, D. (2011). Memoria arqueológica C/ Carrasquer 2-4, Tomo 1 y 2. (Memoria de excavación). Ajuntament de València. Archivo SIAM (Valencia).

Pascual Berlanga, G. (2012). Memoria cientifica. Excavaciones arqueológicas en la C/Palomar 12 de Valencia. (Memoria de excavación). Ajuntament de València. Archivo SIAM (Valencia).

Passelac, M. (1993a). Céramique à parois fines. En M. Py (Dir.). Dicocer [1], Dictionnaire des céramiques antiques (VIIe s. av. n. è.-VIIe s. de n. è.) en Méditerranée nordoccidentale (Provence, Languedoc, Ampurdan). Lattara, 6 (pp.511-521). Lattes: Association pour la recherche archéologique en Languedoc oriental.

Passelac, M. (1993b). Céramique à vernis rouge pompéien. En M. Py (Dir.). Dicocer [1], Dictionnaire des céramiques antiques (VIIe s. av. n. è.-VIIe s. de n. è.) en Méditerranée nord-occidentale (Provence, Languedoc, Ampurdan). Lattara, 6 (pp.545-471). Lattes: Association pour la recherche archéologique en Languedoc oriental.

Passelac, M. y Vernhet, A. (1993). Céramique sigillée sudgauloise. En M. Py (Dir.). Dicocer [1], Dictionnaire des céramiques antiques (VIIe s. av. n. è.-VIIe s. de n. è.) en Méditerranée nord-occidentale (Provence, Languedoc, Ampurdan). Lattara, 6 (pp.569-580). Lattes: Association pour la recherche archéologique en Languedoc oriental.

Peñil Mínguez, J., Lamalfa Díaz, C. y Fernández Ibáñez, C. (1985-1986). Las cerámicas de paredes finas del alfar de Rubielos de Mora (Teruel). Kalathos, 5-6, 189-197.

Pérez Macías, J. A., Delgado Domínguez, A. y Regalado, M. (2012). El asentamiento romano en el paraje de Marismilla (Riotinto-Nerva, Huelva). En J. A. Pérez Macías y J. L. Carriazo (Eds.). Paisajes, tiempo y memoria: acercamientos a la Historia de Andalucía (pp.45-82). Huelva: Universidad de Huelva.

Pérez Outeiriño, B. y Villaluenga Garmendia, M. J. (19911992). Notas sobre mangos con temas dionisíacos en cerámica de «paredes finas» hallados en Mérida. Anas, $I V-V$, 93-103.

Polo Cerdá, M. y García-Prósper, E. (2002). Ritual, violencia y enfermedad. Los enterramientos en decúbito prono de la necrópolis fundacional de Valentia. Saguntum, 34, 137-148. Recuperado de: https://ojs.uv.es/index.php/saguntum/article/ view/1902/1411

Polo Cerdá, M., García-Prósper, E. y De Haro Pozo, H. (2009). El ritual de la cremación en Valentia (ss. II a.C.III d.C.): análisis bioantropológico preliminar. En M. Polo Cerdá y E. García Prósper (Eds.). Investigaciones históricomédicas sobre salud y enfermedad en el pasado. Actas del IX Congreso Nacional de Paleopatología (Morella, 2007) (pp.757-763). Valencia: Sociedad Española de Paleopatología y Grupo Paleolab.

Polo Cerdá, M., García-Prósper, E., Guérin, P. y Villalaín, J. D. (2004). La fundación de Valentia y sus primeros pobladores. Primeras evidencias osteoarqueológicas de tuberculosis en Hispania. En E. Baquedano y S. Rubio Jara (Eds.). Zona
Arqueológica, Vol. III (4) (pp.292-305). Alcalá de Henares: Museo Arqueológico Regional.

Pozo, S. F. (2005). La vajilla metálica de la provincia Baetica. III. La argentería romana. Antiquitas, 17, 33-56.

Py, M. (1993). Céramique campanienne A. En M. Py (Ed.). Lattara 6 (pp.146-150). Lattes: Association pour la recherche archéologique en Languedoc oriental.

Quevedo Sánchez, A. (2012). La ciudad de Carthago Nova (Cartagena, España): paradigma de cambio y transformación urbana en la Hispania medioimperial. Ensayo para una síntesis. Antesteria, 1, 63-77.

Quevedo Sánchez, A. y Bermejo Tirado, J. (2012). Reinterpretación de un contexto material de mediados del siglo III d.C.: la intervención arqueológica de la calle Cuatro Santos n. ${ }^{\circ} 40$ (Cartagena). Pyrenae, 43 (1), 107-133. Recuperado de: http://www.raco.cat/index.php/Pyrenae/ article/view/258913

Raynaud, C. (1993). Céramique africaine Claire D. En M. Py (Ed.). Lattara 6 (pp.190-197). Lattes: Association pour la recherche archéologique en Languedoc oriental.

Remesal Rodríguez, J. (1979). Reseña a D. Colls, R. Etienne, R. Lequément, B. Liou, F. Mayet. L'épave Port-Vendres II et le commerce de la Bétique à l'époque de Claude, Archaeonautica I, Paris 1977. Archeologia classica, 31, 379-378.

Rosselló Mesquida, M. (1993). Informe de la intervención arqueológica en la C/Virgen de la Misericordia 4 (Valencia). (Memoria de excavación). Ajuntament de València. Archivo SIAM (Valencia).

Rosselló Mesquida, M. (2005). El territorium de Valentia en l'Antiguitat tardana. En J. M. Gurt y A. Ribera i Lacomba (Coords.). VI Reunió d'Arqueologia Cristiana Hispànica: les ciutats tardoantigues d'Hispania: cristianització i topografia (València, 2003) (pp.279-304). Valencia: Institut d'Estudis Catalans.

Rosselló Mesquida, M. y Ruiz Val, E. (1996a). La necrópolis occidental de la Valencia romana. Saitabi, 46, 147-168. Recuperado de: http://roderic.uv.es/handle/10550/27115

Rosselló Mesquida, M. y Ruiz Val, E. (1996b). La necrópolis romana de la $\mathrm{C} /$ Virgen de la Misericordia, Valencia. Siglo I a.C.-III d.C. En J. D. Villalaín, C. Gómez y F. Gómez (Coords.). Actas del II Congreso Nacional de Paleopatología (Valencia, 1993) (pp.183-193). Valencia: Asociación Española de Paleopatología - Universitat de Valencia.

Salazar Bonet, J. (2006). Memoria arqueológica calle Murillo 38, Barrio de Velluters. (Memoria de excavación). Ajuntament de València. Archivo SIAM (Valencia).

Salido Domínguez, J. y Rodríguez Ceballos, M. (2015). Figurillas de encapuchados hispanorromanos: Definición, clasificación e interpretación. Archivo Español de Arqueología, 88, 105-125. DOI: https://doi.org/10.3989/aespa.088.015.006

Sánchez Fernández, M. J. (1983). Cerámica común romana del Portus Illicitanus. Lucentum, II, 285-317. DOI: http:// dx.doi.org/10.14198/LVCENTVM1983.2.13 
Soriano, R. (1989). La necrópolis de La Boatella: elementos para su cronología, Saguntum, 22, 393-411. Recuperado de: https://ojs.uv.es/index.php/saguntum/article/view/3687/3266

Vaquerizo Gil, D. (2002-2003). Dos antiguos hallazgos de terracotas figuradas en ambientes funerarios de Corduba: revisión historiográfica, análisis iconográfico y nueva propuesta de interpretación. Anales de Arqueología Cordobesa, 13-14, 311-353.

Vargas Cantos, S. (2002). El conjunto funerario de la Constancia (Córdoba). Ajuares y cronología. En D. Vaquerizo (Ed.). Espacio y usos funerarios en el Occidente romano: actas del Congreso Internacional (Córdoba, 2002) (pp.297-310).
Córdoba: Universidad de Córdoba. Recuperado de: http:// www.cervantesvirtual.com/nd/ark:/59851/bmczg738

Vegas, M. (1973). Cerámica común romana del Mediterráneo Occidental. Barcelona: Instituto de Arqueología y Prehistoria - Universidad de Barcelona.

Vizcaíno Sánchez, J. (2009). La presencia bizantina en Hispania (siglos VI-VII), La documentación arqueológica: el mundo funerario. En R. González Fernández (Dir.). La presencia bizantina en "Hispania» (siglos VI-VII): la documentación arqueológica. Antigüedad y cristianismo Monografias históricas sobre la Antigüedad tardia, XXIV, 535-596. 